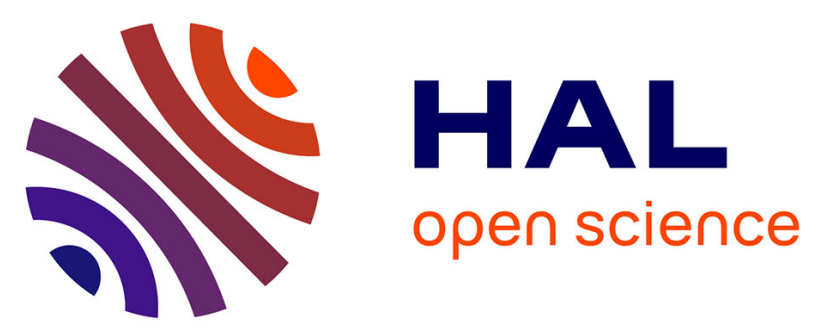

\title{
Mechanical pretreatments of lignocellulosic biomass: towards facile and environmentally sound technologies for biofuels production
}

Abdellatif Barakat, Claire Mayer, Abderrahim Solhy, Rick A. D. Arancon, Hugo de Vries, Rafael Luque

\section{To cite this version:}

Abdellatif Barakat, Claire Mayer, Abderrahim Solhy, Rick A. D. Arancon, Hugo de Vries, et al.. Mechanical pretreatments of lignocellulosic biomass: towards facile and environmentally sound technologies for biofuels production. RSC Advances, 2014, 4 (89), pp.48109-48127. 10.1039/c4ra07568d . hal-01135766

\section{HAL Id: hal-01135766 https://hal.science/hal-01135766}

Submitted on 31 Mar 2015

HAL is a multi-disciplinary open access archive for the deposit and dissemination of scientific research documents, whether they are published or not. The documents may come from teaching and research institutions in France or abroad, or from public or private research centers.
L'archive ouverte pluridisciplinaire HAL, est destinée au dépôt et à la diffusion de documents scientifiques de niveau recherche, publiés ou non, émanant des établissements d'enseignement et de recherche français ou étrangers, des laboratoires publics ou privés. 
CrossMark $\leftarrow$ click for updates

Cite this: RSC Adv., 2014, 4, 48109

Received 24th July 2014

Accepted 18th September 2014

DOI: 10.1039/c4ra07568d

www.rsc.org/advances

\section{Mechanical pretreatments of lignocellulosic biomass: towards facile and environmentally sound technologies for biofuels production}

\author{
Abdellatif Barakat, ${ }^{\text {a }}$ Claire Mayer-Laigle, ${ }^{a}$ Abderrahim Solhy, ${ }^{b}$ Rick A. D. Arancon, ${ }^{c}$ \\ Hugo de Vries ${ }^{a}$ and Rafael Luque ${ }^{c}$
}

The transformation of lignocellulosic biomass into biofuels represents an interesting and sustainable alternative to fossil fuel for the near future. However, one still faces some major challenges for the technology to be fully realized including feedstock costs, novel pretreatment processes, production, transportation, and environmental impact of the full chain. The development of new technologies focused to increase the efficiency of cellulose conversion to biofuels determines successful implementation. Mechanical fractionation is an essential step in order to increase final carbohydrate output, appropriate particle sizes and densification, enzymatic accessibility, and bioconversion affectivity without the production of toxic side streams. In this review article, we surveyed a substantial amount of previous work in mechanical fractionation or pretreatments of a variety of lignocellulosic biomasses; these include numerous milling schemes and extrusions, and their impacts on the physical and physicochemical properties of the lignocellulosic matrix (crystallinity, surface area, particle size, etc). We have also compared results with other pure chemical and physicochemical pretreatments in order to show the new aspects and advantages/disadvantages of such an approach. Last, but not least, the effect
${ }^{a}$ INRA, UMR 1208 Ingénierie des Agropolymères et Technologies Emergentes (IATE) 2, place Pierre Viala - 34060, Montpellier Cedex 1, France. E-mail: barakat@supagro.inra.fr; Fax: +33 (0)4 996130 76; Tel: +33 (0)4 99612581

${ }^{b}$ Université Polytechnique Mohammed VI, Lot 660-Hay Moulay Rachid, 43150, Ben Guerir, Morocco
'Departamento de Química Orgánica, Universidad de Córdoba, Campus de Rabanales, Edificio Marie Curie (C-3) CtraNnal IV-A, Km 396, Córdoba, Spain E-14014

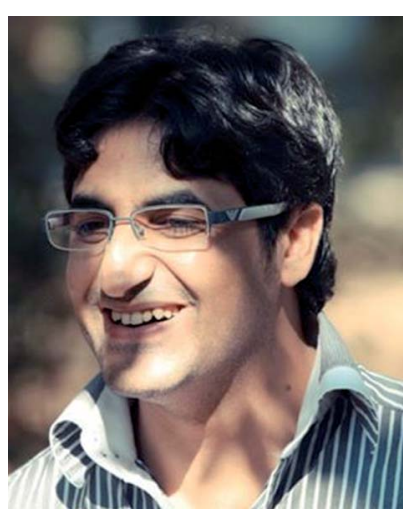

Abdellatif Barakat is a Researcher in Green Chemistry and Engineering of Lignocellulosic Biomass at INRA, JRU of Agropolymer Engineering and Emerging Technologies (IATE, Montpellier, France) which focuses on Dry Fractionation of Agro-resources. He has great experiences in the field of Biochemical and Physicochemical Characterization of Biomass, Dry Fractionation, Chemical and Physicochemical Pretreatments and Bioconversion of Lignocellulosic Biomass to Biofuels, Chemicals and Biomaterials. He received in 2007 his $P h D$ in Chemistry and Physicochemical of Lignocellulosic Biopolymers from Reims University. Before joining the JRU IATE, he effected several Post Doc in France, at Laboratory of Biotechnologies of the Environment (LBE, INRA), in Narbonne (2009-2011), and at Institut Charles Gerhardt (MACS, CNRS) in Montpellier, (2007-2009).

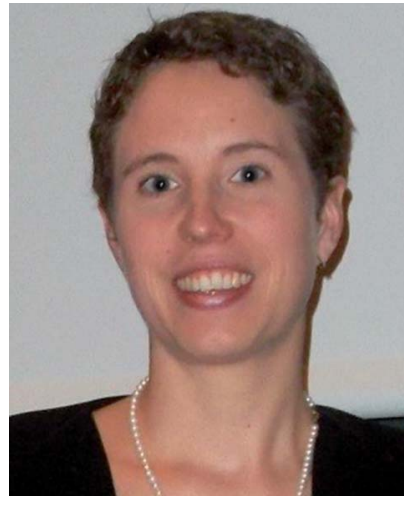

Claire Mayer-Laigle is a Research engineer and Director of the agroresources processing platform of the JRU Agropolymer Engineering and Emerging Technologies (IATE), INRA Montpellier, France. She received her $P h D$ in process and chemical engineering from Toulouse University. She has great experiences in development and optimization of Dry Fractionation of Agro-resources Process and Physicochemical characterization of powders. Before joining the JRU IATE, she worked at RAPSODEE research centre, Albi, France and at Norais Technologies (SME), L'hermitage-Lorge, France. 
of mechanical treatment and physical properties on enzymatic hydrolysis and bioconversion has been discussed, with potentially interesting dry lignocellulosic biorefinery schemes proposed.

\section{Introduction}

Mechanical size reduction is a crucial step for the transformation of feedstock into energy and polymer biomaterials in the field of bio-based products (bioenergy and biomaterials) from renewable biomass resources. ${ }^{1-4}$ Size reduction has many advantages: (i) it increases the volume calorific value of biomass and simplifies the densification processes, ${ }^{5}$ (ii) it simplifies the supply chain of raw materials, ${ }^{6}$ and their storage conditions, (iii) it increases the total accessible surface area and, thus, improves the bio-accessibility of constituents ${ }^{7}$ and the conversion of saccharides during hydrolysis and (iv) it reduces the

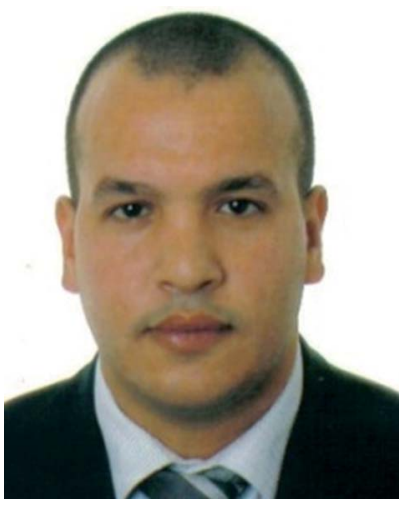

Abderrahim Solhy received his $P h D$ in materials chemistry and heterogeneous catalysis in 2004 from the University of Hassan II Mohammedia and in collaboration with Universidad of Zaragoza, Spain. Right after the thesis, he passed one year in Surface Treatment industry. Then he effected several postdoctorals, at Universidad Publica de Navarra in Spain, at Laboratoire de Chimie de Coordination in Toulouse, France and at Institut Charles Gerhardt in Montpellier. Between July 2008 and February 2009, he worked at MINATEC in Grenoble. Since March 2009, he is project-leader at MAScIR Foundation. He is Laureate of the third edition of the Grand Prize for Invention and Research in Science and Technology in 2010. His current research interests include synthesis of materials and nanomaterials for catalysis and environment and waste and biomass valorization, fields in which with co-workers he has published over 40 papers and 3 patents.

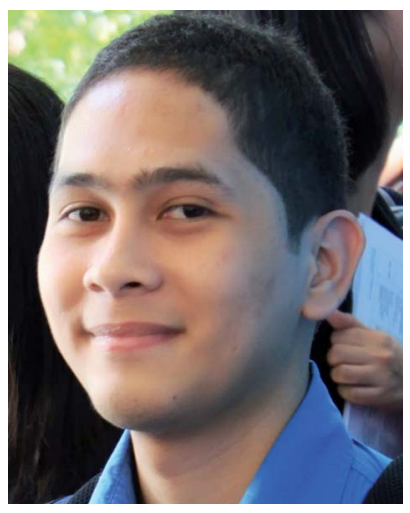

Rick Arneil Arancon finished his BSc in Chemistry at Xavier University - Ateneo de Cagayan in 2011 (Cum Laude). After graduation, he moved to Ateneo de Manila University to accept a Junior Faculty teaching post. In 2013, he moved to the City University of Hong Kong in the group of Dr Carol Lin as a Graduate Teaching Assistant/ Research Fellow for 6 months and to the group of Dr Rafael Luque at the Universidad de Cordoba, Spain. He is currently pursuing his MSc studies under the LANEF Pre-Doctoral Fellowship Program at the Universite Joseph Fourier in Grenoble, France.

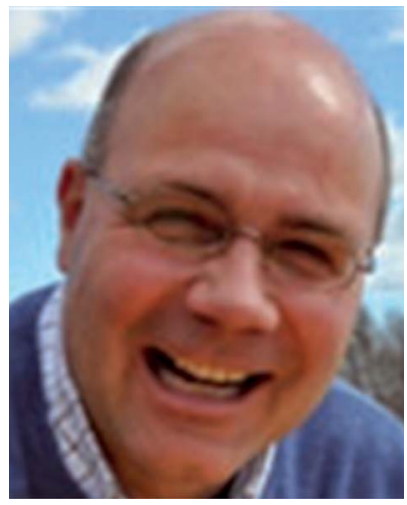

Hugo de Vries is Director of the Joint Research Centre IATE of INRA, CIRAD, SupAgro and University of Montpellier II on Biopolymer Research and Emerging Technologies. JRC is IATE is focusing on dry fractionation, process-structure-function relationships, food-packaging material science, white biotechnology and knowledge engineering. He is Board member EFFoST and of the Chair UNESCO 'alimentation durable'. He is former head of the Food Technology Centre, Wageningen UR, and he has coordinated the European Integrated Project NovelQ. He has a PhD in Physics.

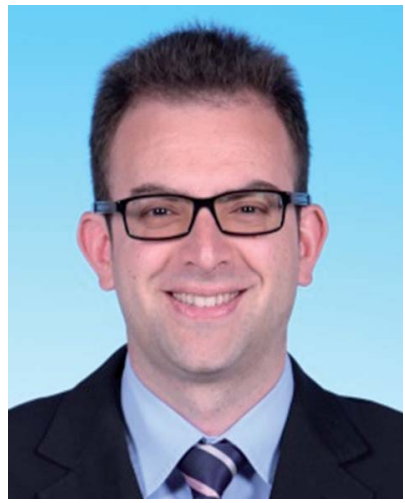

Rafael Luque has extensively contributed to the areas of biomass and waste valorisation practises to materials, fuels and chemicals as well as nanoscale chemistry over the past 10 years, with $>220$ research articles, 3 patent applications and 7 edited books as well as numerous contributions to book chapters and keynote and plenary lectures in scientific events worldwide. Among recent awards, Rafael has received the RSC Environment, Sustainability and Energy Early Career Award (2013), 2013 Distinguished Engineering Fellow from CBME at HKUST in Hong Kong and currently honoured as Chinese Academy of Sciences Visiting Professor at the Changchun Institute of Applied Chemistry. Rafael combines his academic duties with his activities as young entrepreneur after cofounding Green Applied Solutions S.L.U in Cordoba, Spain and more recently involved in Posidonia Oceanica S.L. 


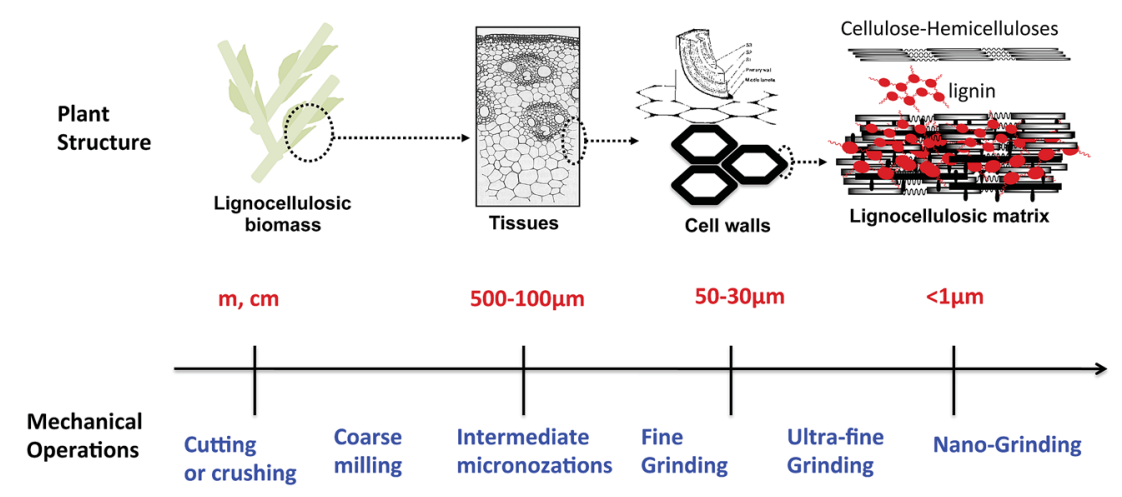

Fig. 1 The different mechanical operations for size reduction of constituents related to plant structure.

mass and heat transfer limitations during the hydrolysis reactions $^{8}$ and consequently reduces energy inputs. ${ }^{1}$ We can distinguish different types of size reduction that are generally differentiated, like cutting or crushing (meter to centimeter range in size), coarse milling ( $\mathrm{cm}$ to $\mathrm{mm}$, $\mathrm{cm}$ to $500 \mu \mathrm{m}$ ), intermediate micronization ( $\mathrm{cm}$ to $100 \mu \mathrm{m})$, fine grinding $(<100$ $\mu \mathrm{m})$, ultra-fine grinding $(<30 \mu \mathrm{m})$ and nanogrinding $(<1 \mu \mathrm{m}){ }^{1,9}$ However, nanogrinding could only be achieved through wet grinding which is not addressed in this contribution due to the associated energy consumption, particularly to dry biomass after the grinding step, far too substantial to consider it a worthwhile pretreatment step (Fig. 1).
The reduction of raw material size is achieved using a combination of different mechanical stresses such as impact, compression, friction, and shear (Fig. 2) - all may coexist in one commercial equipment. ${ }^{1,10,11}$ For example, in a jet mill, the particles are projected against each other in an air stream; major mechanical stresses generated are impact and friction between particles (Fig. 2). Different mill tools are used to fragment and dissociate lignocellulosic biomass: knife mill, hammer mill, pin mill and centrifugal mill, which consist of a rotor driving different tools. The rotor speed is generally adjustable. A sieve or a screen allows control of the particle size of the final product. These mills generate more impact and shear. In ball mills including vibratory
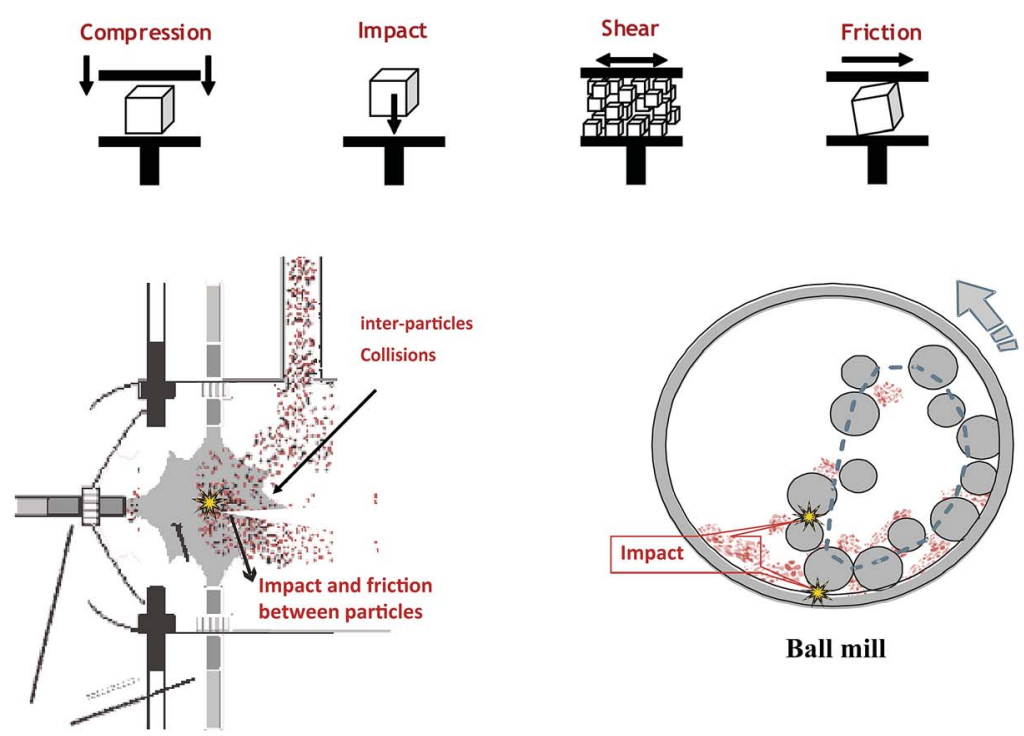

(Jet mill)

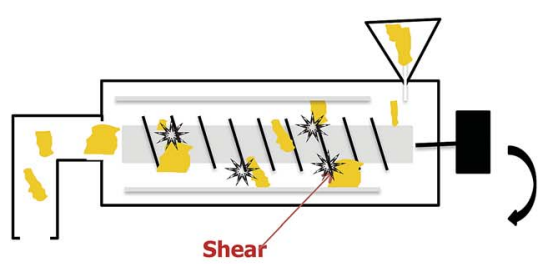

Extruders

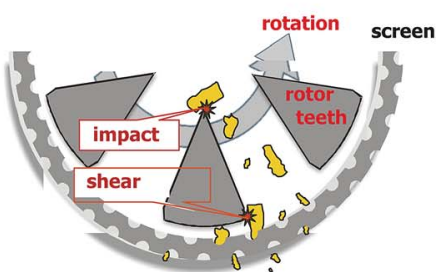

(Knife, centrifugal mill...)

Fig. 2 Schematic representation of some commercial milling equipment with the different mechanical stresses generated. 
ball mill and tumbling ball mills (or planetary ball mills), the raw materials suffer impact and compression stresses when collisions between balls and walls occur. Finally in an extruder, the main mechanical stress is shear occurring between the screw and the walls of the extruder. The choice of equipment depends on many parameters: physical and chemical properties of the biomass, the moisture content, final particle size, the particle size distributions and application targets. Colloid mills and extruders are suitable only for comminuting wet materials with moisture contents over 15-25\%, whereas hammer and knife mills are suitable to pretreat dry biomass with moisture contents up to (10-15\%). ${ }^{1,10}$ Extruders, in comparison with disc and ball mills, have advantages in terms of continuous processing, easy adjustment on-line, and usage in large-scale applications with high throughput. The fluidized bed as superfine grinder has been widely used in various industrial fields for its excellent ability to improve the surface area and enhance the bioavailability of the materials through micronizations, without sacrificing the natural physical-chemical proprieties of the materials. ${ }^{12-14}$

The energy requirement in relation to final particle size is one of the most important economical parameters in the choice of milling equipment. It mainly depends on (i) machine specifications such as motor speed, (ii) storage capacity of the milling chamber, (iii) material throughput characteristics, (iv) initial biomass structure and physical-chemical proprieties (moisture content, chemical composition, tissue composition, postpretreatment etc.); and (vi) particle sizes. ${ }^{\mathbf{1 , 4 , 6 , 1 0 , 1 5}}$ However, the equipment could also be selected for steering the reactivity of biomass. As an example, several studies have shown that BM could be described as a mechanical-chemical treatment because the prolonged milling efficiently breaks chemical bonds between lignin and hemicelluloses, ${ }^{16}$ decrease particle size, ${ }^{17,18}$ decrease the CrI (from 69.9 for raw wheat straw to 23.7 after a BM step), ${ }^{19}$ increase enzymatic hydrolysis ${ }^{\mathbf{1 6 , 1 7}}$ and increase the SSA (from 0.64 for raw wheat straw to $2.3 \mathrm{~m}^{2} \mathrm{~g}^{-1}$ after a BM step). ${ }^{19}$

In this review, we address unique features of extrusion and mechanical size reduction as mechanical pretreatment in lignocellulosic biorefineries. First of all, we outline bioconversion pathways of lignocellulosic materials and we discuss the effect of mechanical treatment compared to the purely chemical and physicochemical treatments with respect to surface area (in relation to enzymatic accessibility) and CrI. In the second part, we discuss the effect of mechanical treatment on enzymatic hydrolysis and the factors that can influence the performances of enzymatic hydrolysis and bioconversion.

\section{Bioconversion of lignocellulosic biomass: from heterogeneous particles to biofuels}

The bioconversion of lignocellulosic biomass has been extensively studied in the past 30 years. In spite of such research endeavors, enzymatic degradation of lignocellulose is still poorly understood because of competing effects including physical properties of the substrate, enzyme synergy and mass transfer. The structural heterogeneity and complexity of cell wall constituents such as crystallinity of cellulose microfibrils, specific surface area of particles and matrix polymers are responsible of the recalcitrance of cellulosic materials (Fig. 3).

Biomass pretreatment is consequently an essential step in order to increase its final carbohydrate output, accessibility, bioavailability and hydrolysis rate (Fig. 3). The objective of pretreatments depends on the process type and biomass structure. For instance, pretreatments aimed to produce biofuels target changes in lignocellulosic matrix properties to make the holocelluloses more accessible to enzymatic attack. ${ }^{20-25}$

Pretreatment methods can be divided into different categories: mechanical, chemical, physicochemical and biological or various combinations of these. Mechanical pretreatments allow the separation of the main botanical parts of the crop into different fractions (tissues, cell, polymers, etc.), to be used as feedstock for various applications. Such pretreatment greatly reduces biomass particle sizes and possibly affects its molecular structure to facilitate enzymatic accessibility. Palmowski and Muller $^{26}$ have studied the effect of mechanical operation on

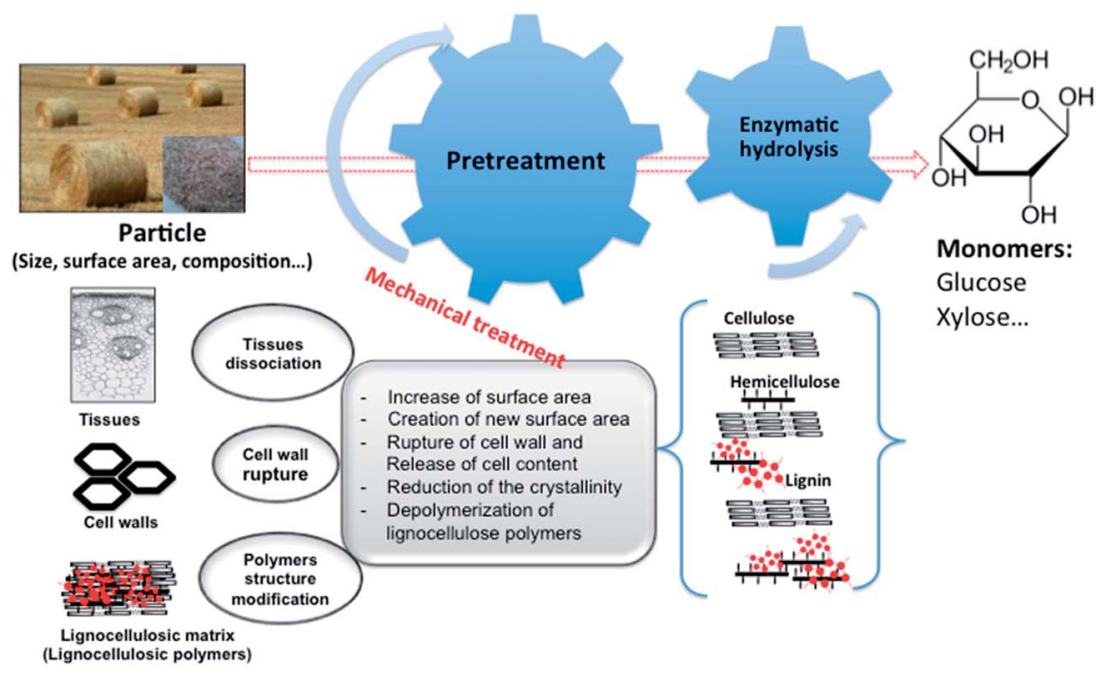

Fig. 3 Different steps of biomass conversion and parameters influencing lignocellulosic particle reactivity. 
different organic samples (apples, rice, sunflower seeds, hay and maple leaves). ${ }^{26}$ After breakdown of these substrates, a significant particle size reduction was observed which is believed to due to the release of soluble organic compounds in solution (cells destroyed through commination and/or dissolution of organic components through newly generated accessible surfaces). ${ }^{26}$ The reduction of particle size could enhance the affinity between cellulose polymers and enzymes and thus increase the rate of hydrolysis. The rate can be doubled in a $10 \mathrm{~h}$ reaction experiment when the average size of cellulose is reduced from 82 to $38 \mu \mathrm{m} .{ }^{27}$ Size reduction also enhances the production of glucose or reducing sugars as illustrated by studies showing a reduction in particle size from 590 to $33 \mu \mathrm{m}$ resulted in a $55 \%$ increase in glucose production after $72 \mathrm{~h}$ cellulose hydrolysis. ${ }^{28}$ It appears that size reduction is an attractive method to increase the yield of hydrolysates from lignocellulosic biomass, especially on the saccharification of plant cell walls by cellulotic enzymes. ${ }^{29}$ Small particle sizes of untreated cellulosic substrate are more readily hydrolyzed as compared to large ones due to their higher specific surface area which gives the enzymes more surface to interact with the substrate during conversion. These hypotheses were tested using ground corn stover in the size ranges of 425-710 and 53-75 $\mu \mathrm{m} .{ }^{29}$ The morphology changes in these particles were imaged after treatment with cellulolytic enzymes before and after liquid hot water pretreatment. The smaller corn stover particles of $53-75 \mu \mathrm{m}$ were $30 \%$ more susceptible to hydrolysis as compared to larger $425-710 \mu \mathrm{m}$ corn stover particles.

Mechanical fractionation is a necessary step in lignocellulosic bioconversion to:

(i) Decrease particle size and increase total accessible specific surface area (SSA).

(ii) Decrease cellulose crystallinity.

(iii) Increase pore size of particles and the number of contact points for inter-particle bonding in the compaction process.

(iv) Dissociation of tissues and rupture of cell wall.

All these parameters improve the digestibility and the conversion of saccharides during hydrolysis., ${ }^{1,21,23,25,30,31}$

\subsection{Effect of mechanical pretreatment on surface area (SSA) and porosity}

The physical properties of the cell wall including its surface specific surface area and porosity play an important role in chemical and biological digestion. ${ }^{32}$ The study of lignocellulosic porosity and specific surface area is a subject of relevant research since molecular probes have been introduced to advance on such important parameters for the conversion of lignocellulosics to fuels and chemicals. Freeze fracture electron microscopy, solute exclusion, mercury porosimetry, electron microscopy (SEM and TEM), NMR, gas adsorption and related tools have been utilized in this regard..$^{32-35}$ The methods conducted to characterize the porosity and specific surface area (SSA) should be carefully considered.

In general terms, the specific surface area and porous texture of biomass can be measured by the adsorption/desorption of a gas (generally $\mathrm{N}_{2}$ ), ${ }^{32,34,36}$ and/or intrusion/extrusion of mercury inside the porous texture of the material (mercury porosimetry).
Mercury porosimetry can also determine pore sizes larger than 3 $\mathrm{nm}$ by using a new generation of automatic mercury porosimeters based on Washburn theory. ${ }^{37}$ Unfortunately, both techniques have their own limitations. Textural porosity (soft or hard) is only identified by adsorption/desorption of gas at the temperature of nitrogen liquefaction $(77 \mathrm{~K})$. Since the sample is previously degassed, several problems could be encountered during the analysis of biomass using nitrogen physisorption, leading to non-representative results. By comparing the effect of solvent polarity and drying temperature of materials, these factors were found to influence the value of BET (theory Brunauer, Emmett and Teller) measurements. ${ }^{38}$ Appropriate solvent drying procedures should also be followed to better maintain capillary structure. ${ }^{38-40}$ The pore volume measured by this technique (adsorption/desorption of gas) is not sufficiently precise for samples containing macropores (pore size greater than $50 \mathrm{~nm}$, corresponding to the relative pressures $P / P_{0}>0.98$, following the Kelvin equation). Lastly, another disadvantage of the nitrogen physisorption relates to the issues to quantify narrow micropores (less than $0.9 \mathrm{~nm}$ ). In this case, other gases such as argon, $\mathrm{CO}_{2}$ or krypton should be used. Mercury porosimetry is comparatively limited to materials with pore diameters under $3 \mathrm{~nm}$. For samples containing micropores and mesopores, the technique adsorption/desorption of $\mathrm{N}_{2}$ is sufficient to characterize the porosity (SSA and pore size). In the case of materials with macropores and mesopores (greater than $3 \mathrm{~nm}$ ), the determination of the specific surface area, as well as pore size distribution must be conducted by analyzing the curves of mercury porosimetry. For materials with a hierarchical porosity (micro-, meso- and macropores), the porosity can be determined by combining nitrogen physisorption and mercury porosimetry. ${ }^{41}$

In general, the purpose of comparing surface areas of materials subjected to different pretreatments can be useful to ascertain whether the pretreatment technology is useful or not. Fig. 4 illustrates the SSA of some treated lignocellulosic substrates, with values within the same range $\left(1-22 \mathrm{~m}^{2} \mathrm{~g}^{-1}\right)$ among all parameters. Interestingly, milling pretreatment was found to give a larger SSA for both types of lignocellulosic materials (Fig. 4). SSA increased for more than $60 \%$ tor wheat straw after BM treatment $(4 \mathrm{~h})$ in comparison to untreated and steam exploded samples. ${ }^{36}$ Piccolo et al.; ${ }^{36}$ found that a more severe steam explosion (SE) treatment $\left(0.2 \% \mathrm{w} / \mathrm{w} \mathrm{H}_{2} \mathrm{SO}_{4}+\mathrm{SE}\right.$ $210{ }^{\circ} \mathrm{C}$ for $10 \mathrm{~min}$ ) increased SSA from 1.9 to $3.1 \mathrm{~m}^{2} \mathrm{~g}^{-1}$. On the other hand, Miao et al.; investigated the mechanical size reduction of miscanthus and switchgrass using a commercialscale hammer mill. SSA of resulting particles were measured using the geometry and density of particles. ${ }^{6}$ This method yielded accessible SSA of $c a .20 .5 \mathrm{~m}^{2} \mathrm{~g}^{-1}$, over 5 times increased under hammer milling treatment as compared to a control experiment and steam explosion treatment. Moreover, BET results showed a relatively low SSA for pretreated lignocellulose. As seen in Fig. 4, SSA of treated miscanthus and switchgrass is highly sensitive to particle size since it increases linearly with increasing particle size. Evidences offered by Zhang et al.;2 support this observation; the authors reported a linear correlation of SSA with pan-milling cycles for cellulose powder as a 


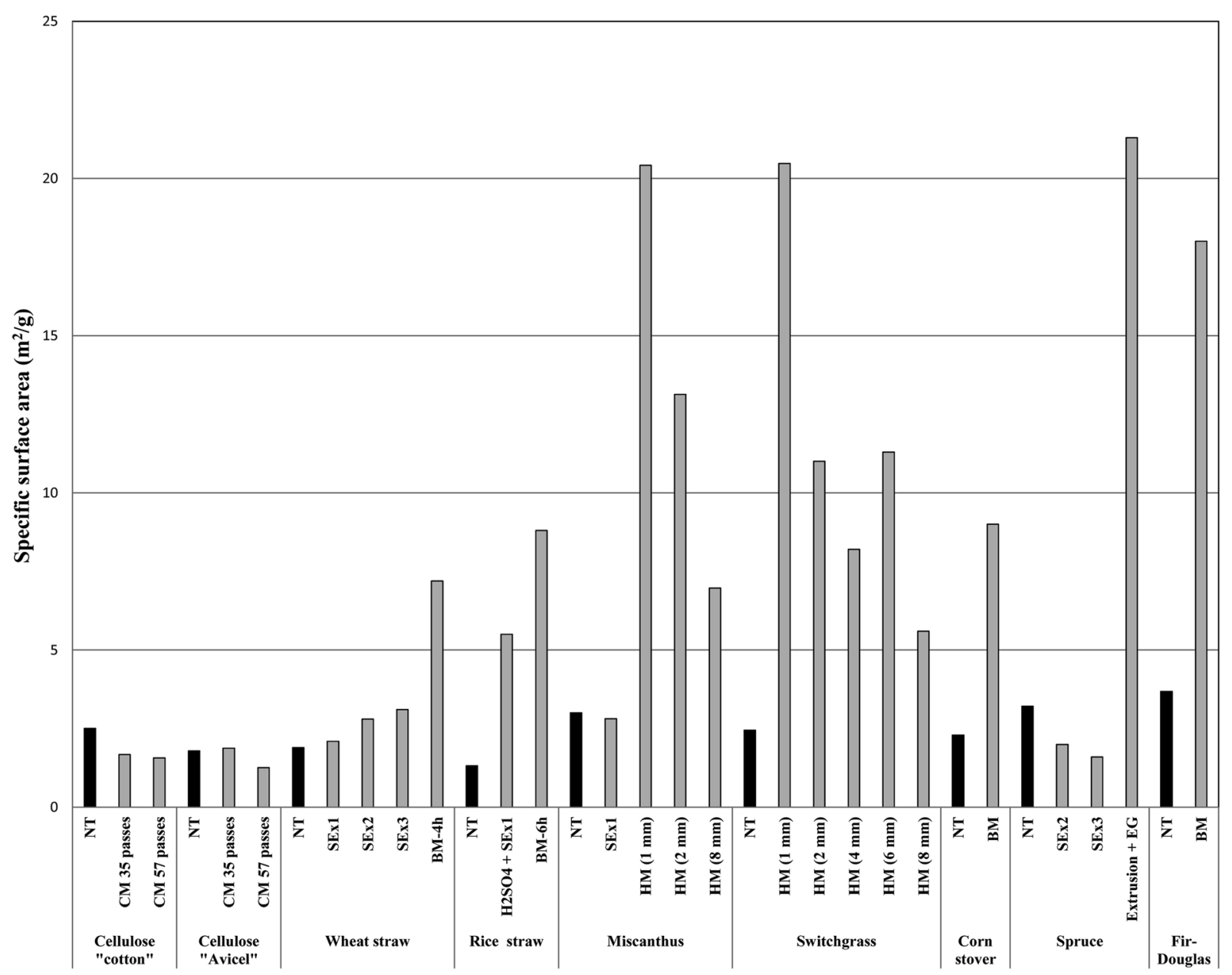

Fig. 4 Effect of mechanical size reduction on specific surface area (SSA) of selected lignocellulosic biomass compared to others pretreatments. NT: not treated; CM: compression milling; BM: ball milling; HM: hammer milling; SEx: steam explosion; EG: ethylene glycol.

consequence of particle size. ${ }^{42}$ These findings indicate that the bundle separation and breakage of fibers into small particles result to larger surface areas at the cut edges. ${ }^{42}$ In a separate study, Miao et al.; ${ }^{6}$ reported fairly low SSA of switchgrass particles pretreated using a $4 \mathrm{~mm}$ milling screen $\left(8.2 \mathrm{~m}^{2} \mathrm{~g}^{-1}\right)$ as compared to those passed through a $6 \mathrm{~mm}$ milling screen (11.3 $\left.\mathrm{m}^{2} \mathrm{~g}^{-1}\right)$. The same phenomenon was observed during compression-milling of cotton and avicell cellulosic materials. ${ }^{43}$ The compression-milling resulted in a slight drop in SSA compared to the controls of various untreated cellulose samples (Fig. 4). A comparison between compression-milled cellulosic materials showed only small differences in SSA. BET methods provided $1.6 \mathrm{~m}^{2} \mathrm{~g}^{-1}$ (treated cotton cellulose) as compared to $2.5 \mathrm{~m}^{2} \mathrm{~g}^{-1}$ for the control, and $1.3 \mathrm{~m}^{2} \mathrm{~g}^{-1}$ for treated avicell cellulose compared to $1.8 \mathrm{~m}^{2} \mathrm{~g}^{-1}$ for the control after 57 passes. Particle agglomeration and collapse of capillary structure due to compressive force may be plausible explanations for these phenomena.

$\mathrm{BM}$ is considered to be the most effective treatment in increasing SSA. In comparison, the duration of BM treatments of rice straw, corn stover, and fir-Douglas wood significantly increased SSA from 1.3 to $8.8 \mathrm{~m}^{2} \mathrm{~g}^{-1}$ for rice straw, 2.3 to
$9.0 \mathrm{~m}^{2} \mathrm{~g}^{-1}$ for corn stover and 3.7 to $18 \mathrm{~m}^{2} \mathrm{~g}^{-1}$ for fir-Douglas wood. Extrusion is an alternative method reported to increase the surface area of biomass. Piccolo et al. $;^{36}$ reported that the fibrillation of spruce wood performed under continuous extrusion at $40{ }^{\circ} \mathrm{C}$ and $120{ }^{\circ} \mathrm{C}$ in the presence of ethylene glycol significantly increased SSA from 3.2 to $21.3 \mathrm{~m}^{2} \mathrm{~g}^{-1}$. However, the SSA remained close to $2 \mathrm{~m}^{2} \mathrm{~g}^{-1}$ when spruce wood was treated under $\mathrm{SO}_{2}$-steam explosion $\left(2.5 \% \mathrm{w} / \mathrm{w} \mathrm{SO}_{2}\right)$ at $210{ }^{\circ} \mathrm{C}$ for $5 \mathrm{~min}$. The extrusion process largely increases SSA of corn stover biomass for enzymatic adsorption. ${ }^{44}$ Scanning electron microscopy studies showed that the cellulose network was changed due to the destruction of the lignin sheath. The reported extrusion protocol was a continuous and cost-effective pretreatment method, combining heating with high shear and mixing opening cell walls at the microscopic scale. SSA of pretreated corn stover was significantly improved with respect to control studies, revealing that extrusion could open the cell wall at the microscopic scale (particularly favorable to obtain higher sugar yields). Karunanithy and Muthukumarappan ${ }^{45}$ studied the effect of extrusion parameters on switchgrass bioconversion. The optimum pretreated switchgrass exhibited a $50 \%$ higher surface area as compared to those of control 
experiments. These data demonstrate that mechanical treatment or fractionation are most effective methods in increasing specific surface area and improving the efficiency of cellulose digestion. The conflicting results may be due to different methods used to determine accessible surface area and on the type and size of enzymes used.

\subsection{Effect of mechanical pretreatment on cellulose crystallinity (CrI)}

Intensive pretreatment in polymers is able to cause destruction of macromolecular chains, which leads to the separation of structural constituents. The displacement of structural elements of polymeric chains is firstly accompanied by the distortion of initial chain packing and loss of ordering. It is widely accepted that highly crystalline cellulose is less accessible to cellulase attack as compared to amorphous cellulose. Crystallinity negatively affects the efficiency of enzymatic contact with cellulose. The measurement of crystallinity index (CrI) in lignocellulosics is not a simple task due to the heterogeneous nature of lignocellulosic feedstocks and the contribution of other amorphous components such as lignin and hemicelluloses.

The crystallinity of cellulose in untreated and treated substrates as measured by X-ray diffraction (XRD) is given in
Fig. 5. Data demonstrate that mechanical treatment significantly reduces the crystallinity of lignocellulose biomass, while several chemical and physicochemical pretreatment increase the crystallinity index (CrI) in comparison with untreated substrates. The effect of compression-milling on the crystallinity of cellulose "cotton and avicell" is highly significant. ${ }^{43,46}$ After 35 milling cycles, CrI decreased from its original value (84 and 81 ) to 75 and $17 \%$ for cotton and avicell cellulose, respectively. Ouajai and Shanks ${ }^{47}$ have studied a BM process on cellulose to determine its effect on the crystallinity index. CrI remained almost unchanged during the first 60 minute BM cycles and started to decrease after $100 \mathrm{~min}$. Final cellulose products with a CrI of $36 \%$ (330 minute BM treatment) was obtained. ${ }^{47}$ In a separate study, CrI of poplar wood was found to decreased by $12 \%$ after an 8 day BM process. ${ }^{15}$ In the initial milling stage $(<5$ days), CrI decreased rapidly, while it only slightly decreased (or even increased) after 5 days due to agglomeration of fine particles. Chemical and physicochemical pretreatments have comparably reported to provide an increase of CrI for wood cellulose as well as several different biomass feedstocks (Fig. 5). Da Silva et al. $;^{18}$ compared the effectiveness of BM and WDM in decreasing CrI of sugarcane straw and bagasse. CrI was found to decrease after 30 and 90 min BM of bagasse (from $30 \%$ to $20 \%$ and $0 \%$ respectively) ${ }^{18}$ which can be

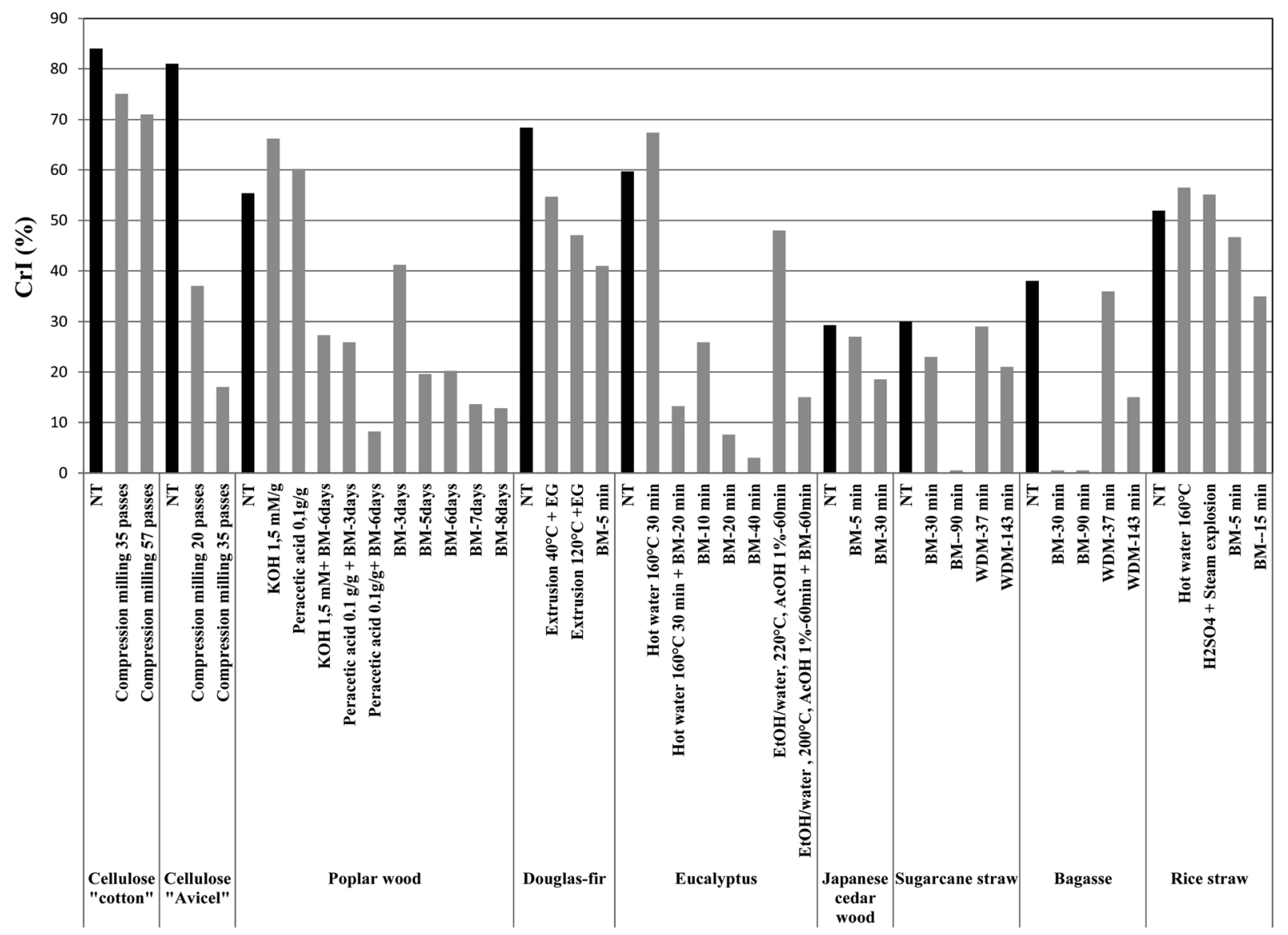

Fig. 5 Effect of mechanical size reduction on crystallinity index $(\mathrm{Crl})$ of selected lignocellulosic biomass compared to others pretreatments (Table 1). NT: not treated; BM: ball milling; WDM: wet disc milling; HM: hammer milling; SEx: steam explosion; EG: ethylene glycol. 
attributed to the complete transformation of crystalline cellulose of sugarcane straw to amorphous cellulose, leading to a significant increase in the extent of enzymatic saccharification. However, CrI decreased slightly in sugarcane straw (28 and 21\%) upon WDM treatment after 37 and 147 min, respectively. BM shows a much higher efficiency in vitrifying crystalline cellulose. A similar effect has been observed when bagasse underwent $\mathrm{BM}$ for $90 \mathrm{~min}$, decreasing CrI from 38 to $0 \%$. Comparatively, BM treatment of rice straw reduces CrI from an initial value of $52 \%$ to $12 \%$ after 60 min milling. ${ }^{48}$ The fibrillation of Douglas fir wood performed by continuous extrusion at $40{ }^{\circ} \mathrm{C}$ and $120^{\circ} \mathrm{C}$ in the presence of additives (ethylene glycol) decreased CrI from 68 to 54 and 47, respectively. CrI also decreased to $41 \%$ upon $\mathrm{BM}$ treatment $(5 \mathrm{~min}$ ) of Douglas fir wood. ${ }^{49}$ These results show that a reduction in crystallinity index depends not only on the initial crystallinity, but also on parameters including the supramolecular organizational structure and the degree of polymerization of cellulose as well as the different mechanical pretreatment (ball-, disk, compression-milling, number of passes, time, etc). The increase in crystallinity is generally proportional to the quantity of solubilized substances during the pretreatment process and could be due to the removal of amorphous regions. With proofs and reports evidencing the influence of CrI on enzyme digestibility, future pretreatment methods should pay attention to the reduction of crystallinity in lignocellulosic materials to maximize fractionation and product yields. One way to effectively decrease the crystallinity of lignicellulosic biomass relates to ball-milling pre-processing. In the next section, this review will discuss key findings and observations with further explanation and theories behind these important topics.

\section{Effect of mechanical treatment on the efficiency of enzymatic hydrolysis}

The rate and extent of enzymatic hydrolysis of lignocellulosic biomass highly depend on enzyme loadings, time and rate of hydrolysis as well as structural features resulting from pretreatments. The influence on biomass digestibility and structural properties varies with changes in enzyme loading, time of hydrolysis and other structural features. Important parameters affecting the hydrolysis include previously discussed factors such as the crystallinity of the material, the accessible surface area, the particle size and lignin distribution. Table 1 compiles a body of data on monomeric sugars yields after enzymatic hydrolysis or EHGY (enzymatic hydrolysis glucose yields) varying with $t$ structural features of substrate, postpretreatments, mechanical operation and time.

\subsection{Milling or mechanical size reduction process}

Zhu et al.;,4 investigated the impact of disk-milling (DM) conditions on the efficiency of enzymatic cellulose saccharification of softwood. EHGY was increased to more than $92 \%$ in glucan after $48 \mathrm{~h}$ enzymatic hydrolysis when wood chips were pretreated by post-SPORL (Sulfite Pretreatment to Overcome Recalcitrance of Lignocellulose) DM (disk-plate gap of $0.76 \mathrm{~mm}$ ) with $2.21 \%$ acid charge (Table 1). ${ }^{3,4}$ Similar effects on EHGY were also achieved using large disk-plate gaps (up to $1.52 \mathrm{~mm}$ ). The same authors also studied the effect of lignin, acetyl content and biomass CrI on the digestibility of poplar wood with various enzyme loadings using post-chemical DM. Lignin content and biomass crystallinity dominated digestibility, but most importantly lignin content was not relevant for digestibility at low crystallinity. Poplar wood treated with $\mathrm{KOH}$ contained $1.5 \mathrm{mmol} \mathrm{g}^{-1}$ of wood and peracetic acid $0.1 \mathrm{~g} \mathrm{~g}^{-1}$; this resulted in a EHGY of $c a .18 \%$ and $6 \%$ with a cellulase loading of 2 FPU per $g$ substrate. Cellulose conversion was only improved upon pretreatment with $\mathrm{KOH}$ and peracetic acid. Optimum conditions for the enzymatic hydrolysis of cellulose (86\%) were achieved using peracetic acid $1 \mathrm{~g} \mathrm{~g}^{-1}$ followed by ball milling for 6 days. Mais et al.;0 studied enzyme hydrolysis on $\alpha$-cellulose as a model substrate and $\mathrm{SO}_{2}$-impregnated steam-exploded Douglas-fir wood chips. ${ }^{50}$ The softwood-derived substrate was further post-treated with hot water and alkaline hydrogen peroxide to remove over $90 \%$ of the original lignin (Table 1 ). The experiments were evaluated under different reaction conditions, including substrate concentration, enzyme loading, reaction volumes and number of ball beads employed during mechanical milling. The authors demonstrated that the use of BM could improve the overall conversion of $\alpha$-cellulose by approx. $12 \%$, increasing the total hydrolysis yield from 70 to $82 \%$. It was apparent that the best conditions for the enzymatic hydrolysis of $\alpha$-cellulose were achieved using a larger number of beads, while the presence of air-liquid interfaces did not seem to affect the rate of saccharification. Similarly, when lignocellulosic substrates were employed, up to $100 \%$ hydrolysis was achieved with a minimum enzyme loading (10 filter paper units per $g$ of cellulose) at lower substrate concentrations and with a greater number of reaction beads during milling. These findings support the importance of the simultaneous combination of $\mathrm{BM}$ and enzymatic hydrolysis to enhance saccharification rates and/or a reduction in enzyme loading required to attain total hydrolysis of the lignocellulosic matrix.

Inoue et $a l . ;{ }^{51}$ examined the enzymatic digestibility of eucalyptus following a combined pretreatment, without using chemicals, comprising ball milling (BM) and hot-compressed water (HCW) treatment. BM treatment simultaneously improved the digestibility of both glucan and xylan, being also effective in reducing enzyme loading as compared to HCW treatment. ${ }^{51}$ The combination of HCW and BM treatments also reduced the usual $\mathrm{BM}$ time (Table 1). Eucalyptus treated with HCW $\left(160{ }^{\circ} \mathrm{C}, 30 \mathrm{~min}\right)$ followed by $\mathrm{BM}$ for 20 minutes had approximately $70 \%$ of EHGY with a cellulase loading of 4 FPU per $\mathrm{g}$ substrate. This yield was comparable to yields from samples treated with $\mathrm{HCW}\left(200{ }^{\circ} \mathrm{C}, 30 \mathrm{~min}\right)$ or those subjected to $\mathrm{BM}$ for $40 \mathrm{~min}$ and further hydrolyzed using ten times higher concentration of cellulases (40 FPU per $\mathrm{g}$ substrate). HCW treatment was therefore very useful in improving the milling efficiency and its combination with BM treatment can save energy and enzyme loading. Teramoto et. al. ${ }^{\mathbf{1 6}}$ developed a sulfuric acid-free ethanol cooking (SFEC) treatment to achieve complete saccharification of cellulosic components in eucalyptus, thereby avoiding the problems associated with the use of 


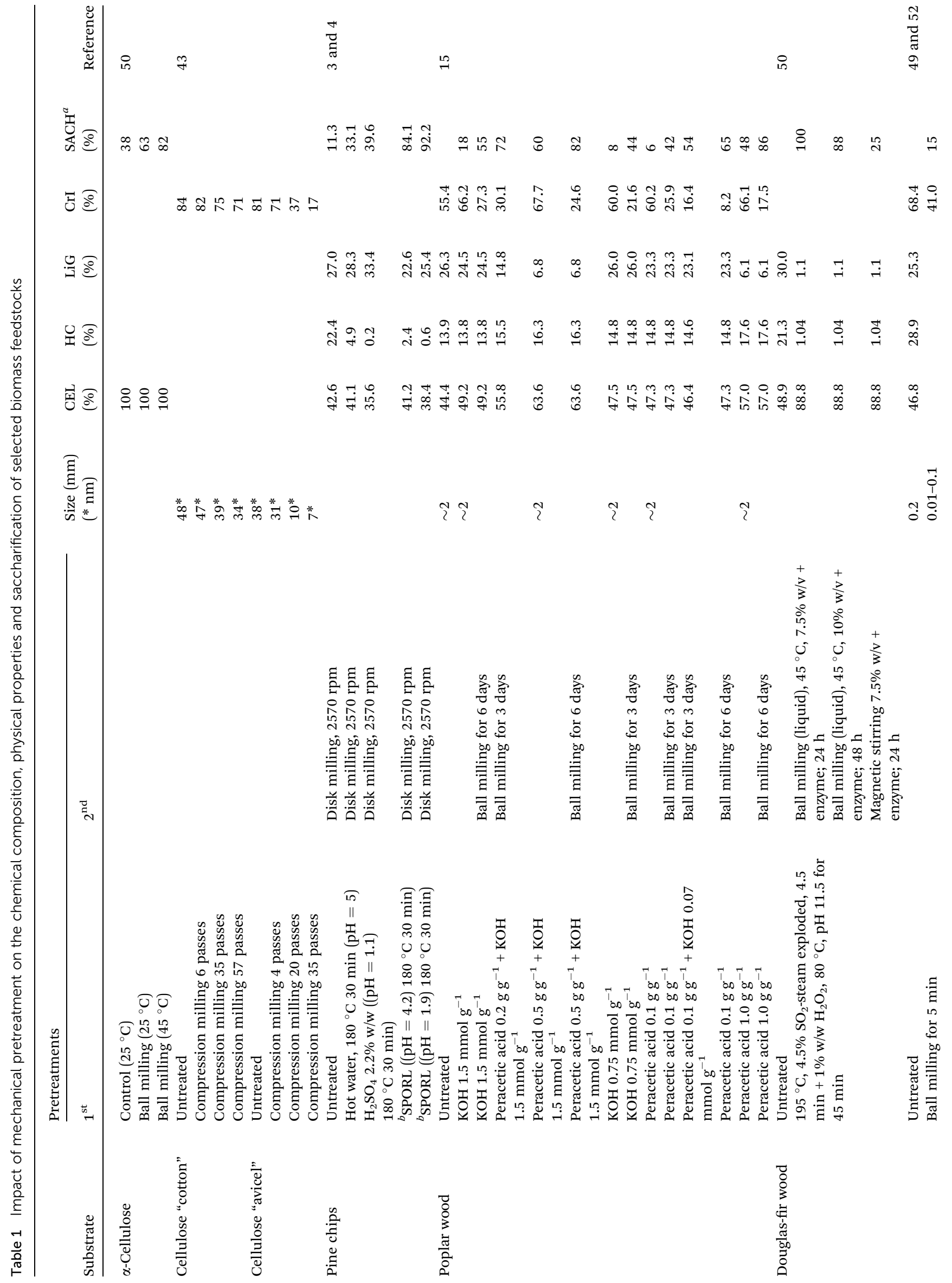




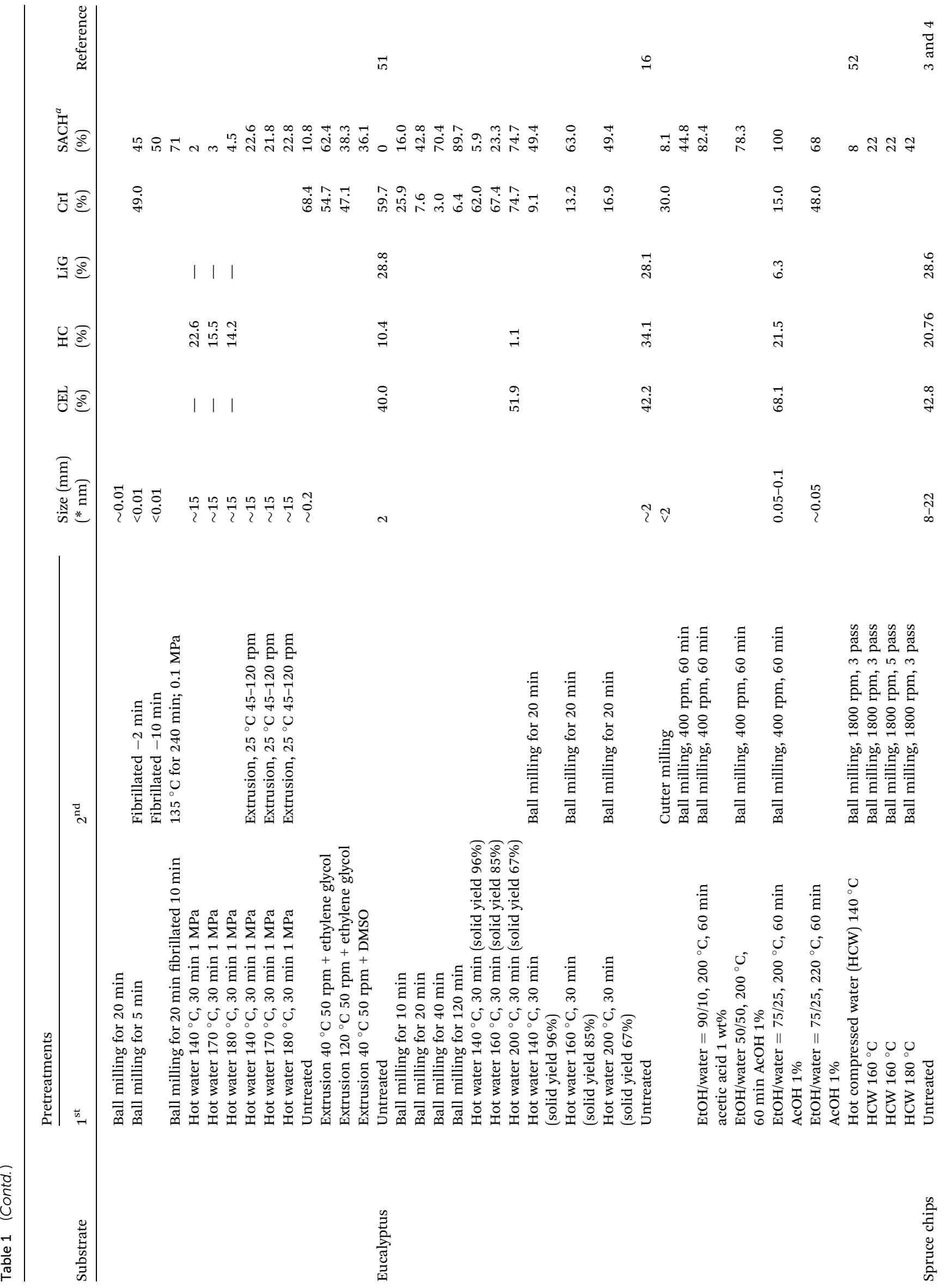




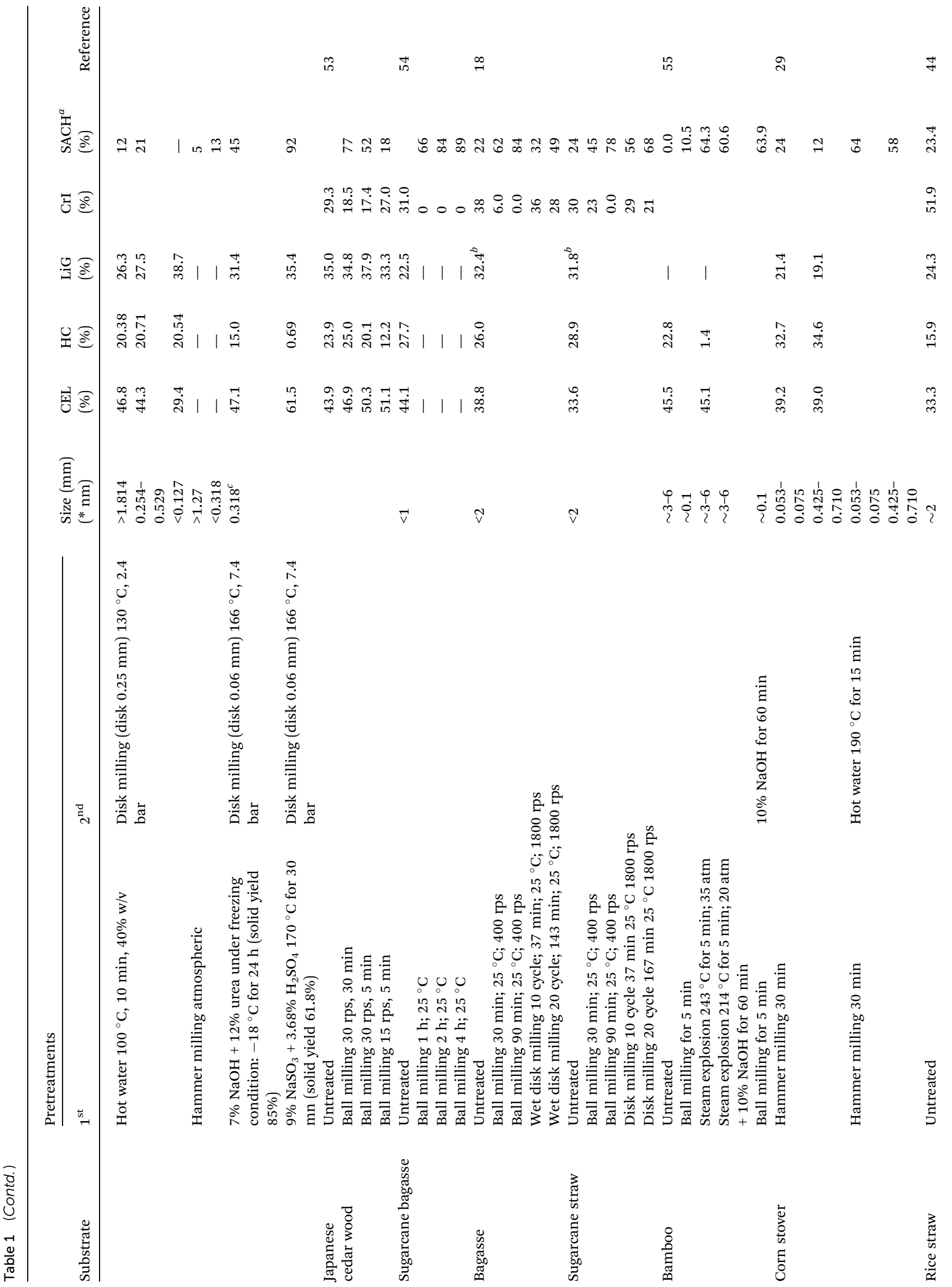




\section{RSC Advances}

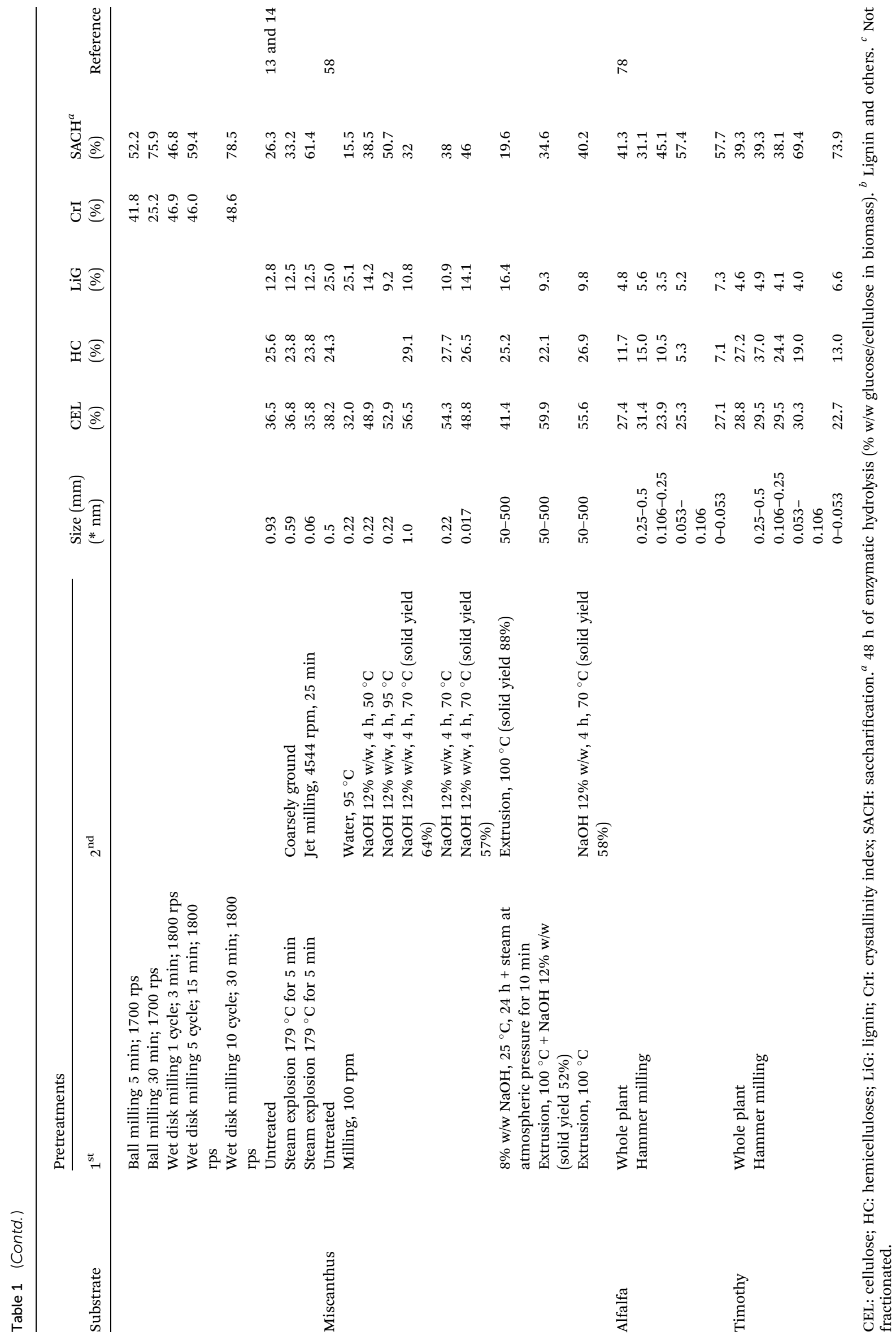


strong acid catalysts. ${ }^{\mathbf{1 6}}$ Cutter-milled flours were exposed to a mixture of ethanol (EtOH)/water/acetic acid mixture in an autoclave. Enzymatic hydrolysis experiments of the postchemical size reduction pre-treated samples demonstrated that almost complete conversion $(100 \%)$ of the cellulosic components to glucose could be achieved under optimum conditions: $\mathrm{EtOH} 50 \%, 200{ }^{\circ} \mathrm{C}$ for $60 \mathrm{~min}$ with $1 \% \mathrm{AcOH}$ followed by $\mathrm{BM}$ for 60 minutes. A large-scale trial revealed that there is little consumption of in-feed EtOH during SFEC, with the possibility to recover and reuse the majority of EtOH.

The effect of DM of HCW-treated water insoluble residues from eucalyptus on EHGY was also recently studied. ${ }^{52}$ Glucose production was observed to increase at increasing number of passes, with the highest EHGY (42.8\%) obtained for 3-pass DM after $\mathrm{HCW}$ treatment at $180^{\circ} \mathrm{C}$. This value can be recalculated to be $101.7 \%$ with cellulose content $(42.1 \%$ of untreated raw material) of the starting material taken as reference, essentially proving all glucan content was digestible.

Studies from our group have been focused in the development of ecofriendly combined treatment using a chemical process and DM as mechanical process. ${ }^{17}$ An innovative dry $\mathrm{NaOH}$ chemo-mechanical pretreatment $\left(\mathrm{TS}_{\mathrm{dry}}\right)$ was conducted at high material concentration $\left(5 \mathrm{~kg} \mathrm{~L}^{-1}\right)$ with a biomass-liquid ratio of $5: 1$. The primary objective of this study was to develop a dry chemo-mechanical pretreatment process which minimises waste generation, reducing the environmental impact of the entire process in conjunction with energy savings and increase enzymatic hydrolysis efficiency. $\mathrm{NaOH}$-dilute chemomechanical $\left(\mathrm{TS}_{\text {dilute }}\right)$ pretreatment conducted at low material concentration $\left(0.2 \mathrm{~kg} \mathrm{~L}^{-1}\right)$ consumed higher amounts of water ( $5 \mathrm{~L}$ water per $1 \mathrm{~kg}$ biomass) and energy compared to $\mathrm{TS}_{\mathrm{dry}}$. In fact, the lowest energy efficiency obtained was $0.417 \mathrm{~kg}$ glucose $\mathrm{kW} \mathrm{h}^{-1}$ for $\mathrm{TS}_{\text {dilute }}$ chemo-mechanical pretreatment as compared to $0.888 \mathrm{~kg}$ glucose $\mathrm{kW} \mathrm{h}{ }^{-1}$ and $0.197 \mathrm{~kg}$ glucose $\mathrm{kW}$ $\mathrm{h}^{-1}$ for $\mathrm{TS}_{\mathrm{dry}}$ and control, respectively. ${ }^{17}$

The accessibility of enzymes to exposed cellulose surfaces of Japanese cedar wood tissues pretreated with $\mathrm{NaOH}, \mathrm{NaOH}-$ $\mathrm{Na}_{2} \mathrm{~S}$ (kraft pulping), hydrothermolysis, ball-milling, and organosolvolysis was also recently studied..$^{53}$ Results clarified the linear dependency of the exposure of crystalline and noncrystalline cellulose surfaces for enzymatic saccharification obtained via organosolv and kraft delignification processes. In comparison, BM for 5-30 min, hydrothermolysis for 30-60 min at $180{ }^{\circ} \mathrm{C}$ and alkaline $\left(3 \% \mathrm{NaOH}+\mathrm{Na}_{2} \mathrm{~S}\right.$ at $180{ }^{\circ} \mathrm{C}$ for $\left.30 \mathrm{~min}\right)$ treatments increased the EHGY up to $77 \%, 15 \%$ and $42 \%$, respectively. Buaban et al. $;^{54}$ in turn studied an integrated process combining mechanical pretreatment by BM, with enzymatic hydrolysis and fermentation of bagasse. ${ }^{54}$ They reported that $\mathrm{BM}$ for $2 \mathrm{~h}$ was sufficient to nearly complete cellulose structural transformation into an accessible amorphous form. Pretreated cellulosic residues were hydrolyzed by a crude enzyme preparation method containing cellulase activity combined with complementary $\beta$-glucosidase activity. EHGY of $84.0 \%$ was obtained after $72 \mathrm{~h}$ at $45{ }^{\circ} \mathrm{C}$ and $\mathrm{pH}$ 5. In another study, da Silva et al. ;8 $^{18}$ compared the effectiveness of BM and wet disk milling (WDM) on treating sugarcane bagasse and straw. ${ }^{18}$ EHGY at optimum conditions for BM-treated bagasse and straw were $84 \%$ and $78 \%$, respectively. Maximum yields for bagasse and straw using DM were $49.3 \%$ for glucose and $68 \%$ for xylose. $\mathrm{BM}$ also improved the enzymatic hydrolysis yield by decreasing the crystallinity. The defibrillation effect observed for WDM samples seems to favor enzymatic conversion. Bagasse and straw BM hydrolysates were fermented by Saccharomyces cerevisiae strains. Ethanol yields from total fermentable sugars using a $\mathrm{C}_{6}$-fermenting strain reached $89.8 \%$ and $91.8 \%$ for bagasse and straw hydrolysates, respectively, and $82 \%$ and $78 \%$ when using a $\mathrm{C}_{6} / \mathrm{C}_{5}$ fermenting strain. Yamashita et al.; ${ }^{55}$ studied the post-physicochemical size reduction as a pretreatment method for enzyme saccharification of bamboo biomass. EHGY of $64 \%$ was obtained after $48 \mathrm{~h}$ of using bamboo steam exploded at $35 \mathrm{~atm}$ for $5 \mathrm{~min}$ and at $243{ }^{\circ} \mathrm{C}$. In addition, pretreatments using $20 \mathrm{~atm}$ and $5 \mathrm{~min}$ steam explosion or $\mathrm{BM}$ for $5 \mathrm{~min}$ followed by a $10 \%(\mathrm{w} / \mathrm{w})$ sodium hydroxide treatment at $121{ }^{\circ} \mathrm{C}$ for $60 \mathrm{~min}$ was executed to enhance the digestibility of the holocelluloses component (Table 1). Both pretreatment methods had a large positive effect on the production of sugars by subsequent enzymatic hydrolysis. In particular, the combined 20 atm steam explosion and $10 \mathrm{wt} \%$ sodium hydroxide treatments obtained the maximum EHGY. Levels obtained were $456 \mathrm{mg} \mathrm{g}^{-1}$ of initial dry sample of glucose and $460 \mathrm{mg} \mathrm{g}^{-1}$ of initial dry sample of reducing sugar. In comparison, the $\mathrm{BM}$ process and $10 \mathrm{wt} \%$ sodium hydroxide treatment produced 383 and $485 \mathrm{mg} \mathrm{g}^{-1}$ of initial dry sample of glucose and reducing sugar, respectively. This pretreatment method requires severe conditions, namely high pressure and high temperature steam explosion in combination with high concentrations of sodium hydroxide. Apparently, BM pretreatment is a somewhat less effective, but a more environmentally friendly method for the enzyme saccharification of bamboo. Lin et $a l .{ }^{56}$ studied the chemical BM pre-treatment followed by enzymatic hydrolysis and fermentation for ethanol production from corn stover biomass. ${ }^{56}$ The obtained results indicated that the yields of glucose and xylose were improved by adding any of the following dilute chemical reagents: $\mathrm{H}_{2} \mathrm{SO}_{4}, \mathrm{HCl}, \mathrm{HNO}_{3}$, $\mathrm{CH}_{3} \mathrm{COOH}, \mathrm{HCOOH}, \mathrm{H}_{3} \mathrm{PO}_{4}$, and $\mathrm{NaOH}, \mathrm{KOH}, \mathrm{Ca}(\mathrm{OH})_{2}$, $\mathrm{NH}_{3} \mathrm{H}_{2} \mathrm{O}$ in the $\mathrm{BM}$ pretreatment of corn stover. The optimal enzymatic hydrolysis efficiencies were obtained using BM in an alkali medium, which can be explained by a possible delignification. The said study showed thus that the BM pretreatment is a robust process. Based on microscope image of BM-pretreated corn stover, the particle size of the material was decreased and the fiber structure was more loosely organized. Afterwards, the results indicate that the treatment effect of wet milling is better than that of dry milling. The optimum parameters used for the milling process were ball speed $350 \mathrm{r} \mathrm{min}^{-1}$, solid-liquid ratio of 1 : 10, raw material particle size with $0.5 \mathrm{~mm}$, and number of balls of 20 (steel ball $=10 \mathrm{~mm}$ ), and grinding for $30 \mathrm{~min}$. Hideno et al. ;8 $^{48}$ compared WDM, BM and hot compressed water treatment (HCWT) of rice straw. These authors reported that EHGY by WDM, BM and HCWT were $78.5 \%$, 89.4\% and 70.3\%, respectively. They also reported that in BM, the EHGY increased with milling time and increased gradually with 10 cycles of DM and leveled off between 10 and 20 cycles. $^{48}$ It must be emphasized that the EHGY for 10 cycles was $78.5 \%$ with an optimal 
milling time of $60 \mathrm{~min}$, temperature of $160{ }^{\circ} \mathrm{C}$ for HCWT and 10 repeated milling operations for WDM. On the basis of the BM treatment of the rice straw, the high glucose yield was achieved in a short operation time compared to eucalyptus. ${ }^{51}$ In the said study, the authors suggested that DM is a promising pretreatment for enzymatic hydrolysis. Peng et al.; ; $^{5}$ used microcrystalline cellulose as substrate to investigate its potential ability of bioconversion in a novel combined pretreatment of ball milling (BM) and/or microwave irradiation (MWI). To achieve the same or higher glucose yield of BM for $3 \mathrm{~h}$ and $6 \mathrm{~h}$, BM for $1 \mathrm{~h}$ with MWI for $20 \mathrm{~min}$ could save $54.8 \%$ and $77.4 \%$ energy consumption, respectively. ${ }^{57}$ Moreover, chemicals were not required in this process. It is concluded that the combination of BM and short time MWI is an environment-friendly, econom-

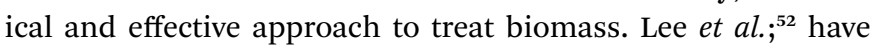
developed an energy efficient nanofibrillation method that combines DM and HCW treatment to improve enzymatic accessibility of Eucalyptus wood. In this method, DM fibrillated the residual product of $\mathrm{HCW}$ treatment under wet conditions. ${ }^{52}$ The relatively moderate HCW treatment conditions (temperature below $180{ }^{\circ} \mathrm{C}$ and reaction time of $30 \mathrm{~min}$ ) were adopted, and the amount of water used was only five times that of wood. These conditions were sufficient for the partial removal of hemicellulose and lignin from cell walls with supramolecular structures to create nano-spaces between cellulose microfibrils. These morphological characteristics have effectively improved the nanofibrillation by DM. The fibrillated products with a size of less than $20 \mathrm{~nm}$ can already be obtained after very short milling time, and this process has significantly improved the enzymatic saccharification yield. The energy consumption is also, notably much lower than that of other mechanical methods for size reduction to give the same monosacchariderecovery yield.

\subsection{Twin screw extrusion process}

The extrusion of biomass can be a viable pretreatment method due to its ability to simultaneously expose it to a range of disruptive conditions in a continuous flow process. Nevertheless, the extruder screw speed, barrel temperature, and feedstock moisture content are important factors that can influence sugar recovery from biomass.

Lee et $a l .{ }^{49}$ studied a mechanical micro/nano-fibrillation of Douglas fir by a continuous extrusion process in an attempt to develop a cost-effective pretreatment method for enzymatic saccharification (Table 1). Additives with cellulose affinity (ethylene glycol, glycerol, and dimethyl sulfoxide) were used to effectively fibrillate the wood cell wall up-to submicron- or nano-scale, thus opening up the cell wall structure for improving enzymatic accessibility, and lowering likewise the extrusion torque. ${ }^{49}$ The fibrillated products were converted into glucose with a high yield by enzymatic saccharification. The maximum cellulose-to-glucose conversion (64\%) was achieved when Douglas fir wood was extruded at $40{ }^{\circ} \mathrm{C}$ in the presence of ethylene glycol. The EHGY was approximately 6 times higher than that of the untreated raw material. Nonetheless, the fibrillation of wood cell walls into submicron and/or nanoscale fibers was successfully carried out in the presence of water using a batch-type kneader in combination with the available twinscrew elements. The maximum EHGY was found to be $54.2 \%$ in the case when the fibrillated products were kneaded for 20 min after ball milling using a screw combination. The fibrillation also increased the surface area of cellulose and the EHGY was improved by cooking the fibrillated products with water at $135{ }^{\circ} \mathrm{C}$ under $0.25 \mathrm{MPa}$. The authors have reported that only mechanical kneading appears to have some limitations towards exposure of cellulose for complete enzymatic saccharification. de Vrije et al. $;^{58}$ investigated the biomass conversion pretreatment methods for the production of fermentable substrates from Miscanthus. The obtained results demonstrated an inverse relationship between lignin content and the efficiency of enzymatic hydrolysis of polysaccharides. ${ }^{58}$ The high delignification values were obtained by the combination of extrusion and chemical pretreatment (sodium hydroxide), which is an optimized process, consisted of a one-step extrusion- $\mathrm{NaOH}$ pretreatment at moderate temperature $\left(70{ }^{\circ} \mathrm{C}\right)$. A mass balance of this process in combination with enzymatic hydrolysis showed that the pretreatments resulted in $77 \%$ delignification, and a cellulose yield of more than 95\% and $44 \%$ hydrolysis of hemicellulose. After enzymatic hydrolysis, 69\% and $38 \%$ of the initial cellulose and hemicellulose fractions, respectively, were converted into glucose, xylose and arabinose. Of the initial biomass, $33 \%$ was converted into monosaccharides. Normal growth patterns of Thermotogaelfii on hydrolysate were observed and high amounts of hydrogen were produced. Yoo et al.;9 investigated the thermo-mechanical extrusion pretreatment for lignocellulosic biomass using soybean hulls as the substrate. Structural changes in substrate and sugar yields from thermo-mechanical processing were compared with two traditional pretreatment methods that utilized dilute acid (1\% sulfuric acid) and alkali (1\% sodium hydroxide). Extrusion processing parameters (temperature, moisture, screw speed) and processing aids (starch, ethylene glycol) were studied with respect to reducing sugar and glucose yields. The conditions resulting in the highest EHGY (95\%) were screw speed of $350 \mathrm{rpm}$, maximum temperature $80{ }^{\circ} \mathrm{C}$ and moisture content of $40 \%$. Compared to untreated soybean hulls, EHGY of soybean hulls increased by $69.6 \%, 128.7 \%$ and $132.2 \%$ when pretreated with dilute acid, alkali and extrusion respectively. ${ }^{59}$ Liu et al.; ${ }^{60}$ investigated the alkaline twin-screw extrusion pretreatment (ATSE) for corn stover. ATSE was conducted with a biomass-liquid ratio of $1 / 2(\mathrm{w} / \mathrm{w})$ at a temperature of $99^{\circ} \mathrm{C}$ without any addition al heating equipment. The results indicate that ATSE pretreatment is effective in improving the enzymatic digestibility of corn stover. Sodium hydroxide loading is a more influential factor affecting both sugar yield and lignin degradation than heat treatment time. ${ }^{60}$ After ATSE pretreatment under the proper conditions $(\mathrm{NaOH}$ loading of $0.06 \mathrm{~g} \mathrm{~g}^{-1}$ biomass during ATSE and 1 hour heat preservation after extrusion), $71 \%$ lignin removal was achieved and the conversions of glucan and xylan in the pretreated biomass can reach up to $83 \%$ and $89 \%$ respectively via subsequent enzymatic hydrolysis (cellulase loading of 20 FPU per g-biomass and substrate consistency of $2 \%$ ). About $78 \%$ of the original 
polysaccharides were converted into fermentable sugars. Kang et $a l .{ }^{61}$ investigated the production of bioethanol from Miscanthus using a specially designed twin-screw extruder with sodium hydroxide. The pretreatment parameters were optimized using a response surface methodology. ${ }^{61}$ Optimum pretreatment conditions were $95{ }^{\circ} \mathrm{C}, 0.4 \mathrm{M}$ sodium hydroxide concentration, $80 \mathrm{rpm}$ twin-screw speed, and flow rate of 120 $\mathrm{mL} \min ^{-1}$. Under these optimum conditions, efficiency of pretreatment through the biomass to ethanol ratio was $66 \%$, as compared to a theoretical maximum of $67 \%$. Duque et al.; ${ }^{62}$ studied an integrated one-step alkaline extrusion process as pretreatment for sugar production from barley straw (BS) biomass. The influence of extrusion temperature $(T)$ and the ratio $\mathrm{NaOH} / \mathrm{BS}$ dry matter $(\mathrm{w} / \mathrm{w})(R)$ into the extruder on pretreatment effectiveness was investigated in a twin-screw extruder at bench scale. The optimum conditions for a maximum EHGY were determined to be $R=6 \%$ and $T=68{ }^{\circ} \mathrm{C}$. At these conditions, glucan yield reached close to $90 \%$ of theoretical yields, while xylan conversion was $71 \%$ of theoretical values. ${ }^{62}$ These values are 5 and 9 times higher than that of the untreated material. Zhang et al.; ${ }^{\mathbf{5 6 , 6 3}}$ investigated the extrusion methodology, as a continuous and cost-effective pretreatment method for corn stover bioconversion. The objective of this study was to examine the effect of extrusion as a pretreatment method and the underlying factors ruling the improvement of sugar yields. ${ }^{56,63}$ The optimum glucose, xylose, and combined sugar recoveries were $48.79 \%, 24.98 \%$, and $40.07 \%$, respectively, at $27.5 \%$ moisture content and $80 \mathrm{rpm}$ screw speed. These yields were 2.2, 6.6, and 2.6 times higher than those for untreated corn stover. Karunanithy et al. ${ }^{64}$ investigated the effects of extrusion parameters on pretreatment of pine wood chips. Pine wood chip at 25,35 , and $45 \%$ moisture content were pretreated at various temperatures $\left(100,140\right.$, and $\left.180{ }^{\circ} \mathrm{C}\right)$ and screw speeds $(100,150$, and $200 \mathrm{rpm})$ using a screw with compression ratios of $3: 1$. The pretreated pine wood chips were subjected to standard enzymatic hydrolysis followed by sugar and byproducts quantification. ${ }^{64}$ Pine wood chips pretreated at a screw speed of $150 \mathrm{rpm}$ and a temperature of $180^{\circ} \mathrm{C}$ with a moisture content of $25 \%$ resulted in a maximum cellulose, hemicellulose, and total sugar recoveries of 65.8, 65.6, and $66.1 \%$, respectively, which was about $6.7,7.9$, and 6.8 fold higher than the control. Furthermore, potential fermentation inhibitors such as furfural, hydroxyl methyl furfural, and acetic acid were not found in any of the treatment combinations. Karunanithy and Muthukumarappan ${ }^{45}$ used the switchgrass as a substrate to study the effect of moisture content $(10,20,30,40$, and $50 \%)$ and particle size $(2,4,6,8$, and $10 \mathrm{~mm})$ over a range of temperatures and screw speeds (45-225 ${ }^{\circ} \mathrm{C}$ and $\left.20-200 \mathrm{rpm}\right)$. Statistical analyses revealed that among the independent variables considered, temperature, screw speed, and moisture content had significant effect on sugar recoveries. ${ }^{45}$ The optimum pretreatment condition of temperature $176{ }^{\circ} \mathrm{C}$, screw speed $155 \mathrm{rpm}$, moisture content $20 \%$, and particle size $8 \mathrm{~mm}$ resulted in maximum glucose $(41.4 \%)$, xylose $(62.2 \%)$, and combined sugar recoveries $(47.4 \%)$. The optimum pretreated switchgrass samples had 50\% higher surface area than that of the control. Karunanithy et al.;65,66 investigated also the influence of alkali $(\mathrm{NaOH})$ concentration on sugar recovery and optimized the extruder temperature, screw speed, and particle size for maximum sugar recovery. In order to evaluate the sequential effect of alkali soaking and extrusion, prairie cord grass $(2-10 \mathrm{~mm})$ was soaked at different alkali concentrations $(0.5-2.5 \%, \mathrm{w} / \mathrm{v} \mathrm{NaOH})$ for $30 \mathrm{~min}$ at room temperature and then extruded using a lab scale single screw extruder at various temperatures $\left(45-225^{\circ} \mathrm{C}\right)$ and screw speeds $(20-200 \mathrm{rpm})$. All the independent variable had a strong influence on sugar recovery and it was confirmed through statistical analyses. ${ }^{\mathbf{6 5 , 6 6}}$ The optimal pretreatment condition $114{ }^{\circ} \mathrm{C}, 122 \mathrm{rpm}$ screw speed, $1.70 \%$ alkali concentration, and $8 \mathrm{~mm}$ particle size resulted in maximum glucose, xylose and combined sugar recoveries of $86.8,84.5$, and $82 \%$, respectively.

\section{Discussion}

Enzymatic hydrolysis of cellulosic biomass depends on many factors such as physical proprieties of the substrate (chemical composition, CrI, degree of polymerization, SSA, lignin content, synergy between enzymes, mass transfer, substrate adsorption, pore diffusion, etc.). ${ }^{17,30,46,57,67-69} \mathrm{O}^{\prime}$ Dwyer et al. ${ }^{70}$ has proposed an empirical model that describes the roles of wheat straw lignocellulosic properties in enzymatic hydrolysis (digestibility $\left.=2.04 \mathrm{SSA}^{0.99}(100-\mathrm{CrI}) \mathrm{LiG}^{-0.39}\right)$. Lignin (LiG) content, SSA and CrI have the greatest impact on biomass (for wheat or even for all biomass) digestibility. It is widely accepted that highly crystalline cellulose is less accessible to cellulase attack than amorphous cellulose; therefore, crystallinity negatively affects the efficiency of enzyme contact with cellulose. ${ }^{71-74} \mathrm{~A}$ common method of reducing crystallinity is BM (Fig. 5 and 6), which tends to decrease the particle size and increase the SSA simultaneously. ${ }^{75}$

It can be observed in Fig. 6 that for all the pretreated wood parts, CrI was not directly correlated with the overall saccharification yield. It is hard to deduce whether the increase in enzymatic digestibility was solely due to the reduction in crystallinity or was caused by other physical changes. Some researchers proposed that the effect of reduced crystallinity on the hydrolysis rate might actually be a consequence of increased SSA $^{18,19}$ or decreased particle size. ${ }^{39}$ da Silva et al. ${ }^{18}$ demonstrated that sugar yield after WDM increased while there was an observed decrease in the CrI value. The authors suggest that the number of operation cycles resulting in reduction of particles size and fiber thickness, was the relevant factor in the improvement of enzymatic digestibility of the pretreated materials. The reduction in fiber thickness, which increases the SSA for the attack of cellulase, may play a role as important as the CrI increase. As a comparison, rice straw that underwent ball-milling presented a CrI of $8 \%$ and resulted in glucose yields of $63.6 \%$ after digestion, whereas 20-cycles WDM straw presented a CrI of $21 \%$, but resulted in a higher glucose yield of $68 \%$. Chang et al., (1997) have shown that a further reduction of particle size below 40-mesh does not necessarily enhance the hydrolysis rate. Some studies have also shown that accessible SSA is a crucial factor that affects biomass digestibility. ${ }^{39,76,77}$ Other studies have reported conflicting results on the effect of 


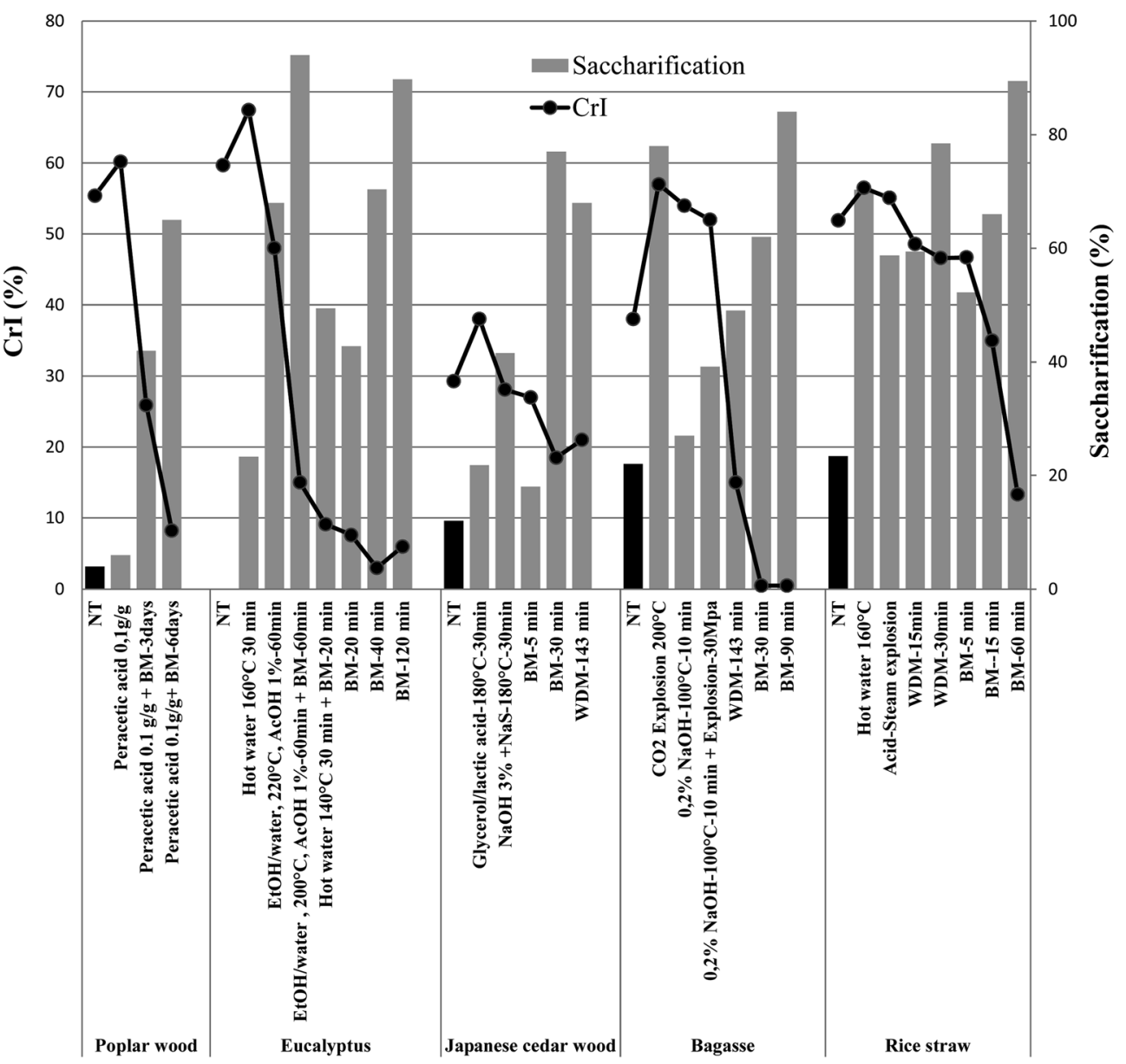

Fig. 6 Relationship between crystallinity index (Crl) and saccharification of selected lignocellulosic biomass (Table 1) NT: not treated; BM: ball milling; HM: hammer milling.

accessible SSA on biomass digestibility. Fan et al.; $;^{72}$ concluded that SSA had no effect on the digestibility of biomass but on limiting enzymatic hydrolysis. ${ }^{19,76}$ In contrast, Zhang et al. ${ }^{63}$ using extrusion, suggested that X-ray diffraction analysis showed that the CrI was not a good indicator of sugar yield. However, scanning electron microscopy showed that the cellulose network was impacted due to the destruction of the lignin sheath exposing the cellulose even more, making it more susceptible to enzymatic hydrolysis. Peng et al. ${ }^{57}$ suggested that the correlation of crystallinity index (CrI), size of crystal, specific surface area (SSA) and degree of polymerization (DP) with the rate of enzymatic hydrolysis is differentiated by an optimized equation that indicates the rate of hydrolysis is much more sensitive as a factor to CrI than to SSA and DP. ${ }^{57}$ Other studies also suggest that lignin content and biomass crystallinity has dominated digestibility. Lignin removal greatly enhanced the ultimate hydrolysis extent. However, the crystallinity reduction tremendously increased the initial hydrolysis rate and reduced the hydrolysis time or the amount of enzyme required to attain high digestibility. To some extent, the effects of structural features on digestibility were interrelated. At short hydrolysis periods, lignin content was not important for digestibility when the crystallinity was low. Similarly, at long hydrolysis periods, the crystallinity was not important to digestibility when lignin content was low. These conflicting results may be due to different methods used to determine lignin content, CrI and SSA; for example $\mathrm{N}_{2}$ adsorption versus solute exclusion method, and methods based on geometry of particles and bulk density used to determine SSA. The measurement of accessible SSA and CrI also depends on the size and organized structure of biomass used. Moreover, accessible SSA and CrI are not easily manipulated in pretreatments.

Anyway, to reveal the underlying relationship of structural features and biomass digestibility, it is important to investigate the influence of each one on the rate and extent of hydrolysis. However, the complex biomass structure confounds the understanding of the relative importance of these features, because altering one structural feature often results in substantial changes in others. In addition, previous studies investigating the influence of structural features on digestibility have been restricted to the measurement of either one or two structural features with one cellulase loading. To eliminate the cross effects among structural features, selective pretreatment techniques have been employed to vary one particular structural feature during a pretreatment, while the other two structural features remained unchanged. 


\section{Conclusion and perspectives for the future: environmental dry- pretreatment lignocellulosic biorefineries}

This contribution has been aimed to demonstrate the versatility of various pretreatment processes for lignocellulosic biomass conversion to biofuels. The complexity of pretreatment steps for an eventual energetic valorization of the biomass was illustrated with a number of examples that provides relevant alternatives to traditional (physic)chemical pretreatments with generally promising (and even improved) results.

Currently, relevant lignocellulosic biomass projects are under development including those of Futurol France, Leuna Germany (http://www.research-in-germany.de/dachportal/en/ Research-Areas-A-Z/Plants/Programmes-andInitiatives/ModernBiorefinery-for-Climate-Protection-and-Resource-

Efficiency.html) and a recently granted COST Action on the conversion of lignocellulosic waste streams to valuable chemicals and fuels (http://www.cost.eu/domains_actions/fps/ Actions/FP1306). However, major challenges including feedstock costs, feedstock variability, production, environmental impacts, water recycling, transportation, enzymes costs, preprocessing along with the development of new technologies with increased efficiency of lignocellulosic conversion still need to be resolved before successful implementation of an integrated lignocellulosic valorisation for fuels, materials and chemicals production.

Mechanical pretreatments have been considered to be one of the most expensive processing steps in biorefinery in terms of energy and operating costs. In general, size reduction processes have a high-energy requirement and are often not economically advantageous. The recommended particle size should be less than $3 \mathrm{~mm}$ for effective accessibility and hydrolysis of lignocellulosic materials. To counteract these disadvantages, size reduction processes through milling, grinding, and extrusion can be combined with chemical and physicochemical pretreatments to save energy for grinding and enzyme loading.
Chemical or physicochemical pretreatments followed by mechanical processing can be considered as interesting innovative methodologies to reduce energy, particle sizes, increase surface area, decrease cellulose crystallinity and increase biomass digestibility and bioconversion. The benefits in energy savings achieved using this combined physicochemical/ mechanical size reduction pretreatment approach are significant, based on previous studies. Energy consumption for agricultural biomass size reduction was reported to significantly decrease with steam exploded substrates. ${ }^{11}$ The specific energy required to grind steam exploded oat and wheat straws, using 3.2 and $1.6 \mathrm{~mm}$ hammer mill screen sizes, was 52 and $25 \%$, and 90 and $64 \%$ lower than untreated straw, respectively. Another study investigated the influence of torrefaction, an oxygen-free mild thermal treatment, on wood grinding energy. ${ }^{79,80}$ Results pointed out that the specific energy consumption for grinding was remarkably reduced with increased torrefaction temperatures for pine, spruce and beech chips. Grindability of torrefied pine chips was substantially improved after torrefaction at 275 ${ }^{\circ} \mathrm{C}$ and $300{ }^{\circ} \mathrm{C}$ as well as the specific energies required for grinding (24-52 $\mathrm{kW} \mathrm{h} \mathrm{t}^{-1}$ ), while the energy consumption to grind non-torrefied spruce and beech chips was as high as 750 $\mathrm{kW} \mathrm{h} \mathrm{t}{ }^{-1}$ and $850 \mathrm{~kW} \mathrm{~h} \mathrm{t}{ }^{-1}$, respectively. ${ }^{79,80}$ Recently Zhu et $a l .{ }^{81}$ studied the effects of chemical pretreatments and diskmilling conditions on energy consumption for size-reduction of softwood. They found that combined chemical-sizereduction pretreatments of forest biomass can reduce grinding energy consumption by $20-80 \%$, depending on the utilised pretreatment under conditions corresponding to $20 \%$ solids-loading and a disk-plate gap of $0.76 \mathrm{~mm}$ under milling. Barakat et al. ; $^{17}$ also reported a reduction in energy consumption $\left(240 \mathrm{~kW} \mathrm{~h} \mathrm{t}^{-1}\right)$ for ball mill-treated wheat straw $(\mathrm{NaOH}$ at 25 ${ }^{\circ} \mathrm{C}$ for $5 \mathrm{~h}$ ) as compared to a superior $485 \mathrm{~kW} \mathrm{~h} \mathrm{t}{ }^{-1}$ energy consumed under ball milled wheat straw without chemical treatment.

The coupling of mechanical size reduction with chemical and physicochemical pretreatments strongly suggest that the digestibility is substantially improved (with a concomitant decrease in energy requirements) while preserving

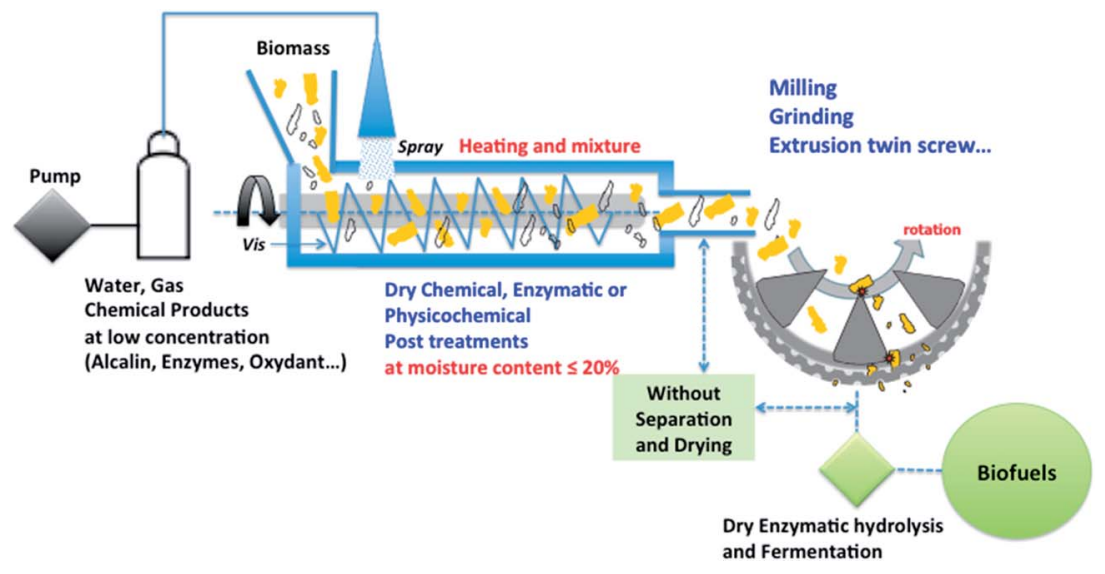

Fig. 7 Future schematic representation of a potentially feasible environmental dry lignocellulosic biorefinery. 
lignocellulosic polymers. These would improve the whole process economics, clearly indicating that combined pretreatments are very important for the reduction of energy consumption in $d r y$ lignocellulosic biorefineries.

The thermal energy consumption for conventional chemical and physicochemical (steam explosion, organosolv, etc) pretreatment is almost linearly proportional to liquid-biomass ratio; thus, reducing this ratio is a prerequisite to improve energy efficiency and limit water utilization and production of (toxic) waste and side streams. In this regard, dry chemical/ physicochemical and biological "solid state" pretreatments combined with dry fractionation steps can be key for advanced pretreatment processes in the future, of direct use in downstream processing in the absence of any solvents/conditioning steps or even separation. Coupling mechanical treatments with dry chemical, physicochemical and/or biological processing (enzymatic hydrolysis and fermentation) in a continuous flow-through process can reduce significantly the energy requirement by $2-5$ times, decrease particle size by $2-5$ times while increasing lignocellulosic conversion and reduce water utilization by $5-10$ times minimizing waste production.

The example illustrated in Fig. 7 showcases the possibilities of the proposed 'dry' biorefinery scheme that may be potentially applicable to the transformation of a wide range of lignocellulosic feedstocks for more efficient and environmentally sound processing.

We believe these technologies can significantly contribute to a more sustainable biomass processing in the future, being part of industrial ventures in our aim to develop multidisciplinary processes equally efficient, cost competitive and with improved environmental footprint to those derived from petrol-based resources that we have relied upon the past $50+$ years.

\section{List of abbreviations}

$\begin{array}{ll}\text { BM } & \text { Ball milling } \\ \text { WDM } & \text { Wet disc milling } \\ \text { DM } & \text { Disk milling } \\ \text { HCWT } & \text { Hot compressed water treatment } \\ \text { SE } & \text { Steam explosion } \\ \text { EHGY } & \text { Enzymatic hydrolysis glucose yield } \\ \text { CrI } & \text { Crystallinity index } \\ \text { SSA } & \text { Specific surface area }\end{array}$

\section{References}

1 A. Barakat, H. de Vries and X. Rouau, Bioresour. Technol., 2013, 134, 362-373.

2 L. Cadoche and G. D. Lopez, Biol. Wastes, 1989, 30, 153-157. 3 J. Y. Zhu, X. Pan and R. S. Zalesny Jr, Appl. Microbiol. Biotechnol., 2010, 87, 847-857.

4 J. Y. Zhu and X. J. Pan, Bioresour. Technol., 2010, 101, 49925002.

5 P. McKendry, Bioresour. Technol., 2002, 83, 37-46.
6 Z. Miao, T. E. Grift, A. C. Hansen and K. C. Ting, Ind. Crops Prod., 2011, 33, 504-513.

7 B. C. Vidal, B. S. Dien, K. C. Ting and V. Singh, Appl. Biochem. Biotechnol., 2011, 164, 1405-1421.

8 D. J. Schell and C. Harwood, Appl. Biochem. Biotechnol., 1994, 45-46, 159-168.

9 G. G. D. Silva, M. Couturier, J. G. Berrin, A. Buleon and X. Rouau, Bioresour. Technol., 2012, 103, 192-200.

10 L. Kratky and T. Jirout, Chem. Eng. Technol., 2011, 34, 391399.

11 P. Adapa, L. Tabil and G. Schoenau, Biomass Bioenergy, 2011, 35, 549-561.

12 W. S. Choi, H. Y. Chung, B. R. Yoon and S. S. Kim, Powder Technol., 2001, 115, 209-214.

13 S. Jin and H. Chen, Biochem. Eng. J., 2006, 30, 225-230.

14 S. Jin and H. Chen, Process Biochem., 2007, 42, 188-192.

15 J. Y. Zhu, G. S. Wang, X. J. Pan and R. Gleisner, Chem. Eng. Sci., 2009, 64, 474-485.

16 Y. Teramoto, N. Tanaka, S. H. Lee and T. Endo, Biotechnol. Bioeng., 2008, 99, 75-85.

17 A. Barakat, S. Chuetor, F. Monlau, A. Solhy and X. Rouau, Appl. Energy, 2014, 113, 97-105.

18 A. S. A. da Silva, H. Inoue, T. Endo, S. Yano and E. P. S. Bon, Bioresour. Technol., 2010, 101, 7402-7409.

19 M. M. Gharpuray, Y. H. Lee and L. T. Fan, Biotechnol. Bioeng., 1983, 25, 157-172.

20 R. Kumar and C. E. Wyman, Biotechnol. Bioeng., 2009, 102, 457-467.

21 F. Monlau, A. Barakat, E. Trably, C. Dumas, J. P. Steyer and H. Carrere, Crit. Rev. Environ. Sci. Technol., 2013, 43, 260322.

22 N. Mosier, C. Wyman, B. Dale, R. Elander, Y. Y. Lee, M. Holtzapple and M. Ladisch, Bioresour. Technol., 2005, 96, 673-686.

23 M. Galbe and G. Zacchi, Pretreatment of lignocellulosic materials for efficient bioethanol production, in Biofuels, ed. L.Olsson, Springer-Verlag Berlin, Berlin, 2007, vol. 108, pp. 41-65.

24 M. Galbe and G. Zacchi, Biomass Bioenergy, 2012, 46, 70-78.

25 M. J. Taherzadeh and K. Karimi, Int. J. Mol. Sci., 2008, 9, 1621-1651.

26 L. M. Palmowski and J. A. Muller, Water Sci. Technol., 2003, 47, 231-238.

27 Q. Gan, S. J. Allen and G. Taylor, Process Biochem., 2003, 38, 1003-1018.

28 R. K. Dasari and R. E. Berson, Appl. Biochem. Biotechnol., 2007, 137-140, 289-299.

29 M. Zeng, N. S. Mosier, C. P. Huang, D. M. Sherman and M. R. Ladisch, Biotechnol. Bioeng., 2007, 97, 265-278.

30 L. Zhu, J. P. O'Dwyer, V. S. Chang, C. B. Granda and M. T. Holtzapple, Bioresour. Technol., 2008, 99, 3817-3828.

31 L. M. Palmowski and J. A. Muller, Water Sci. Technol., 2000, 41, 155-162.

32 A. Chesson, P. T. Gardner and T. J. Wood, J. Sci. Food Agric., 1997, 75, 289-295.

33 G. Papa, M. Spagnol, F. Tambone, R. Pilu, B. Scaglia and F. Adani, Chemosphere, 2010, 78, 1036-1041. 
34 P. T. Gardner, T. J. Wood, A. Chesson and T. Stuchbury, J. Sci. Food Agric., 1999, 79, 11-18.

35 C. Rondeau-Mouro, D. Defer, E. Leboeuf and M. Lahaye, Int. J. Biol. Macromol., 2008, 42, 83-92.

36 C. Piccolo, M. Wiman, F. Bezzo and G. Liden, Enzyme Microb. Technol., 2010, 46, 159-169.

37 E. Washburn, Proc. Natl. Acad. Sci. U. S. A., 1921, 7, 115-116.

38 A. N. Papadopoulos, C. A. S. Hill and A. Gkaraveli, Holz Roh Werkst., 2003, 61, 453-456.

39 H. E. Grethlein, Nat. Biotechnol., 1985, 3, 155-160.

40 W. R. Grous, A. O. Converse and H. E. Grethlein, Enzyme Microb. Technol., 1986, 8, 270-280.

41 C. P. R. Alié, A. J. Lecloux, J. P. Pirard, C. Alié, R. Pirard, A. J. Lecloux and J. P. Pirard, J. Non-Cryst. Solids, 1999, 246, 216-228.

42 W. Zhang, M. Liang and C. Lu, Cellulose, 2007, 14, 447-456. 43 D. D. Y. Ryu, S. B. Lee, T. Tassinari and C. Macy, Biotechnol. Bioeng., 1982, 24, 1047-1067.

44 Y. Zhang, X. Fu and H. Chen, Bioresour. Technol., 2012, 121, 100-104.

45 C. Karunanithy and K. Muthukumarappan, Ind. Crops Prod., 2011, 33, 188-199.

46 I. C. Hoeger, S. S. Nair, A. J. Ragauskas, Y. Deng, O. J. Rojas and J. Y. Zhu, Cellulose, 2013, 20, 807-818.

47 S. Ouajai and R. A. Shanks, Cellulose, 2006, 13, 31-44.

48 A. Hideno, H. Inoue, K. Tsukahara, S. Fujimoto, T. Minowa, S. Inoue, T. Endo and S. Sawayama, Bioresour. Technol., 2009, 100, 2706-2711.

49 S. H. Lee, Y. Teramoto and T. Endo, Bioresour. Technol., 2009, 100, 275-279.

50 U. Mais, A. R. Esteghlalian, J. N. Saddler and S. D. Mansfield, Appl. Biochem. Biotechnol., 2002, 98, 815-832.

51 H. Inoue, S. Yano, T. Endo, T. Sakaki and S. Sawayama, Biotechnol. Biofuels, 2008, 1, 1-9.

52 S.-H. Lee, S. Inoue, Y. Teramoto and T. Endo, Bioresour. Technol., 2010, 101, 9645-9649.

53 T. Kawakubo, S. Karita, Y. Araki, S. Watanabe, M. Oyadomari, R. Takada, F. Tanaka, K. Abe, T. Watanabe, Y. Honda and T. Watanabe, Biotechnol. Bioeng., 2010, 105, 499-508.

54 B. Buaban, H. Inoue, S. Yano, S. Tanapongpipat, V. Ruanglek, V. Champreda, R. Pichyangkura, S. Rengpipat and L. Eurwilaichitr, J. Biosci. Bioeng., 2010, 110, 18-25.

55 Y. Yamashita, M. Shono, C. Sasaki and Y. Nakamura, Carbohydr. Polym., 2010, 79, 914-920.

56 Z. X. Lin, H. Huang, H. M. Zhang, L. Zhang, L. S. Yan and J. W. Chen, Appl. Biochem. Biotechnol., 2010, 162, 1872-1880.

57 H. Peng, H. Li, H. Luo and J. Xu, Bioresour. Technol., 2013, 130, 81-87.
58 T. de Vrije, G. G. de Haas, G. B. Tan, E. R. P. Keijsers and P. A. M. Claassen, Int. J. Hydrogen Energy, 2002, 27, 13811390.

59 J. Yoo, S. Alavi, P. Vadlani and V. Amanor-Boadu, Bioresour. Technol., 2011, 102, 7583-7590.

60 C. Liu, E. van der Heide, H. S. Wang, B. Li, G. Yu and X. D. Mu, Biotechnol. Biofuels, 2003, 6, 97-100.

61 K. E. Kang, M. Han, S. K. Moon, H. W. Kang, Y. Kim, Y. L. Cha and G. W. Choi, Fuel, 2013, 109, 520-526.

62 A. Duque, P. Manzanares, I. Ballesteros, M. J. Negro, J. M. Oliva and F. Saez, Process Biochem., 2013, 48, 775-781.

63 S. Zhang, D. R. Keshwani, Y. Xu and M. A. Hanna, Ind. Crops Prod., 2012, 37, 352-357.

64 C. Karunanithy, K. Muthukumarappan and W. R. Gibbons, Appl. Biochem. Biotechnol., 2012, 167, 81-99.

65 C. Karunanithy and K. Muthukumarappan, Biochem. Eng. J., 2011, 54, 71-82.

66 C. Karunanithy and K. Muthukumarappan, J. Biobased Mater. Bioenergy, 2011, 5, 520-531.

67 L. Zhu, J. P. O'Dwyer, V. S. Chang, C. B. Granda and M. T. Holtzapple, Bioresour. Technol., 2010, 101, 4971-4979.

68 D. Ciolacu, F. Ciolacu and V. I. Popa, Marcromolecular Symposia, 2008, 272, 136-142.

69 J. A. Rollin, Z. G. Zhu, N. Sathitsuksanoh and Y. H. P. Zhang, Biotechnol. Bioeng., 2011, 108, 22-30.

70 J. P. O'Dwyer, L. Zhu, C. B. Granda, V. S. Chang and M. T. Holtzapple, Biotechnol. Prog., 2008, 24, 283-292.

71 V. S. Chang and M. T. Holtzapple, Appl. Biochem. Biotechnol., 2000, 84-86, 5-37.

72 L. T. Fan, Y. H. Lee and D. R. Beardmore, Biotechnol. Bioeng., 1981, 23, 419-424.

73 D. P. Koullas, P. F. Christakopoulos, D. Kekos, B. J. Macris and E. G. Koukios, Cellul. Chem. Technol., 1990, 24, 469-474.

74 D. P. Koullas, S. G. Tsimas and E. G. Koukios, Cellul. Chem. Technol., 1989, 23, 53-61.

75 D. F. M. W. E. Caulfield, Wood Sci., 1974, 6, 375-379.

76 A. P. Sinitsyn, A. V. Gusakov and E. Y. Vlasenko, Appl. Biochem. Biotechnol., 1991, 30, 43-59.

77 D. N. Thompson, H. C. Chen and H. E. Grethlein, Bioresour. Technol., 1992, 39, 155-163.

78 P. Alvo and K. Belkacemi, Bioresour. Technol., 1997, 61, 185198.

79 V. Repellin, A. Govin, M. Rolland and R. Guyonnet, Biomass Bioenergy, 2010, 34, 923-930.

80 M. Phanphanich and S. Mani, Bioresour. Technol., 2011, 102, 1246-1253.

$81 \mathrm{~W}$. Zhu, J. Y. Zhu, R. Gleisner and X. J. Pan, Bioresour. Technol., 2010, 101, 2782-2792. 